OPEN ACCESS

Edited by:

Frank Edgar Muller-Karger. University of South Florida,

United States

Reviewed by:

Scott Doney,

University of Virginia, United States

Philip Bresnahan,

University of California, San Diego,

United States

${ }^{*}$ Correspondence:

Bronte Tilbrook

bronte.tilbrook@csiro.au

Specialty section:

This article was submitted to

Ocean Observation,

a section of the journal

Frontiers in Marine Science

Received: 09 November 2018

Accepted: 03 June 2019

Published: 19 June 2019

Citation:

Tilbrook $B$, Jewett $E B$, DeGrandpre $M D$,

Hernandez-Ayon JM, Feely RA, Gledhill DK, Hansson L, Isensee K, Kurz ML, Newton JA, Siedlecki SA, Chai F, Dupont S, Graco M, Calvo E, Greeley D, Kapsenberg L, Lebrec M,

Pelejero C, Schoo KL and

Telszewski M (2019) An Enhanced

Ocean Acidification Observing

Network: From People to Technology

to Data Synthesis and Information

Exchange. Front. Mar. Sci. 6:337.

doi: 10.3389/fmars.2019.00337

\section{An Enhanced Ocean Acidification Observing Network: From People to Technology to Data Synthesis and Information Exchange}

\author{
Bronte Tilbrook ${ }^{1,2 *}$, Elizabeth B. Jewett ${ }^{3}$, Michael D. DeGrandpre ${ }^{4}$, \\ Jose Martin Hernandez-Ayon ${ }^{5}$, Richard A. Feely ${ }^{6}$, Dwight K. Gledhill ${ }^{3}$, Lina Hansson ${ }^{7}$, \\ Kirsten Isensee ${ }^{8}$, Meredith L. Kurz ${ }^{3}$, Janet A. Newton ${ }^{9}$, Samantha A. Siedlecki10, \\ Fei Chai ${ }^{11,12}$, Sam Dupont ${ }^{13}$, Michelle Graco ${ }^{14}$, Eva Calvo ${ }^{15}$, Dana Greeley, \\ Lydia Kapsenberg ${ }^{15}$, Marine Lebrec ${ }^{7}$, Carles Pelejero ${ }^{15,16}$, Katherina L. Schoo ${ }^{8}$ and \\ Maciej Telszewski ${ }^{17}$ \\ ${ }^{1}$ Commonwealth Scientific and Industrial Research Organisation, Oceans and Atmosphere, Hobart, TAS, Australia, \\ ${ }^{2}$ Antarctic Climate and Ecosystems Cooperative Research Centre, University of Tasmania, Hobart, TAS, Australia, ${ }^{3}$ Ocean \\ Acidification Program, National Oceanic and Atmospheric Administration, Silver Spring, MD, United States, ${ }^{4}$ Department \\ of Chemistry and Biochemistry, University of Montana, Missoula, MT, United States, ${ }^{5}$ Instituto de Investigaciones \\ Oceanológicas, Universidad Autónoma de Baja California, Ensenada, Mexico, ${ }^{6}$ Pacific Marine Environmental Laboratory, \\ National Oceanic and Atmospheric Administration, Seattle, WA, United States, ${ }^{7}$ Ocean Acidification International \\ Coordination Centre, International Atomic Energy Agency Environment Laboratories, Monaco, Monaco, ${ }^{8}$ Intergovernmental \\ Oceanographic Commission of the United Nations Educational, Scientific and Cultural Organization, Paris, France, ${ }^{9}$ Applied \\ Physics Laboratory and College of the Environment, University of Washington, Seattle, WA, United States, ${ }^{10}$ Department \\ of Marine Sciences, University of Connecticut, Groton, CT, United States, " State Key Laboratory of Satellite Ocean \\ Environment Dynamics, Second Institute of Oceanography, Ministry of Natural Resources, Hangzhou, China, ${ }^{12}$ School of \\ Marine Sciences, University of Maine, Orono, ME, United States, ${ }^{13}$ Department of Biological and Environmental Sciences, \\ University of Gothenburg, Kristineberg, Sweden, ${ }^{14}$ Instituto del Mar del Perú, Lima, Peru, ${ }^{15}$ Institut de Ciències del Mar, \\ Consejo Superior de Investigaciones Científicas, Barcelona, Spain, ${ }^{16}$ Institució Catalana de Recerca i Estudis Avançats, \\ Barcelona, Spain, ${ }^{17}$ Institute of Oceanology of the Polish Academy of Sciences, Sopot, Poland
}

A successful integrated ocean acidification (OA) observing network must include (1) scientists and technicians from a range of disciplines from physics to chemistry to biology to technology development; (2) government, private, and intergovernmental support; (3) regional cohorts working together on regionally specific issues; (4) publicly accessible data from the open ocean to coastal to estuarine systems; (5) close integration with other networks focusing on related measurements or issues including the social and economic consequences of $\mathrm{OA}$; and (6) observation-based informational products useful for decision making such as management of fisheries and aquaculture. The Global Ocean Acidification Observing Network (GOA-ON), a key player in this vision, seeks to expand and enhance geographic extent and availability of coastal and open ocean observing data to ultimately inform adaptive measures and policy action, especially in support of the United Nations 2030 Agenda for Sustainable Development. GOA-ON works to empower and support regional collaborative networks such as the Latin American Ocean Acidification Network, supports new scientists entering the field with training, mentorship, and equipment, refines approaches for tracking biological impacts, and stimulates development of lower-cost methodology and technologies 
allowing for wider participation of scientists. GOA-ON seeks to collaborate with and complement work done by other observing networks such as those focused on carbon flux into the ocean, tracking of carbon and oxygen in the ocean, observing biological diversity, and determining short- and long-term variability in these and other ocean parameters through space and time.

Keywords: Global Ocean Acidification Observing Network, Sustainable Development Goal, ocean acidification, ecosystem stressors, capacity building

\section{INTRODUCTION}

The ocean has absorbed approximately $30 \%$ of anthropogenic carbon dioxide $\left(\mathrm{CO}_{2}\right)$ emissions since the industrial era began (Intergovernmental Panel on Climate Change (IPCC), 2013). Ocean acidification (OA), or the ongoing observed increase in marine acidity, is a direct result of this uptake (Doney et al., 2009; Intergovernmental Panel on Climate Change (IPCC), 2013). The average surface ocean $\mathrm{pH}$ has decreased by approximately 0.11 units from a preindustrial mean value of 8.17 , this represents an increase of about $28 \%$ in hydrogen ion concentration (Intergovernmental Panel on Climate Change (IPCC), 2013). By the end of this century, surface ocean $\mathrm{pH}$ is expected to decline by another $0.1-0.4$ units, and carbonate ion $\left(\mathrm{CO}_{3}{ }^{2-}\right)$ concentration is expected to decline by as much as $50 \%$ over the same period compared to preindustrial conditions (Feely et al., 2004; Orr et al., 2005; Doney et al., 2009; Gattuso et al., 2015).

Ocean acidification has the potential to impact marine organisms in a variety of ways, including effects from decreased $\mathrm{pH}$, elevated partial pressure of $\mathrm{CO}_{2}\left(\mathrm{pCO}_{2}\right)$, and decreases in the calcium carbonate $\left(\mathrm{CaCO}_{3}\right)$ saturation state. Changes in the $\mathrm{CaCO}_{3}$ saturation state (Feely et al., 2004) make conditions corrosive for many calcifying organisms such as many species of molluscs, corals, echinoderms, and calcifying plankton, with potential dissolution of calcareous structures such as shells or skeletons (Eyre et al., 2018; Harvey et al., 2018). Changing carbonate chemistry also impacts the process of calcification in many species (Kroecker et al., 2013; Albright et al., 2016; Bednaršek et al., 2017). Less direct impacts can occur where declines in calcification of key habitat forming organisms result in ecosystem shifts and loss of the structural complexity and biodiversity of coral reefs and other benthic communities (Fabricius et al., 2014; Sunday et al., 2016). Negative impacts of changing ocean carbonate chemistry have already been observed in calcifying organisms living in some regions of coastal upwelling where natural acidity is relatively high (Bednaršek et al., 2014, 2017). Research also suggests that changing ocean chemistry and reduced $\mathrm{pH}$ may affect the physiology, behavior, and population dynamics of many non-calcifying species (Doney et al., 2009; Gattuso et al., 2015).

Over the past decade, the OA research community has grown rapidly, and the number of publications related to OA has grown exponentially (Figures 1, 2). In the context of this burgeoning growth, the ocean observing community recognized a need for global coordination at OceanObs'09 (Feely et al., 2010) and has since made progress on collaborative efforts. The potential impacts to marine ecosystems have resulted in OA becoming one of only ten targets for the United Nations (UN) Sustainable Development Goal (SDG) 14 on the conservation and sustainable use of marine resources. The World Meteorological Organization has also included $\mathrm{OA}$ as a headline climate indicator, recognizing the link to increasing atmospheric carbon dioxide concentrations and the climate system. The challenges facing OA researchers, current and future coordinating activities, and a vision in light of the upcoming United Nations Decade of Ocean Science for Sustainable Development (2021-2030) for future OA observing are discussed in this white paper.

\section{CHALLENGE}

The adaptive capacity of organisms that may be impacted by changing ocean chemistry is not well known, and a great deal of work must be done to understand the interactions of multiple stressors and their potential ramifications for marine ecosystems and the human communities that depend on their health. Further, while OA due to an increased atmospheric $\mathrm{CO}_{2}$ concentration occurs in all marine waters, carbonate chemistry in coastal waters is affected by additional processes, such as nutrient addition and its effect on respiration, meaning that coastal acidification may be driven by more factors than just the increase in atmospheric $\mathrm{CO}_{2}$.

The longest time-series observing assets to date have been deployed within several open-ocean environments where they have documented surface water $\mathrm{pCO}_{2}$ values mostly tracking the long-term trend in rising atmospheric $\mathrm{CO}_{2}$ (Figure 3), demonstrating that the global ocean carbon storage has increased since 2000 (Blunden et al., 2018; Feely et al., 2018; Le Quéré et al., 2018). Recent observations within shelf waters have been shown in some regions to lag atmospheric $\mathrm{CO}_{2}$, indicating a tendency for enhanced shelf uptake of atmospheric $\mathrm{CO}_{2}$ from the aqueous phase into biomass (Laruelle et al., 2018). Other coastal regions exhibit more rapid increases in $\mathrm{pCO}_{2}$ relative to the open ocean, indicating more rapid acidification due to the additive effects of $\mathrm{CO}_{2}$ uptake and increased upwelling (Chavez et al., 2017). Coastal seas have been suggested to have changed in the recent past from a net source to a net sink (Bauer et al., 2013; Fennel et al., 2018; Laruelle et al., 2018). The enhanced uptake of $\mathrm{CO}_{2}$ by the ocean and shelves also changes the rate at which waters acidify, altering local rates of acidification, a process not well simulated by coarse global simulation models nor adequately captured by many direct measurements from the existing observing system. The local processes that govern these modifications may also serve to amplify (or dampen) global 

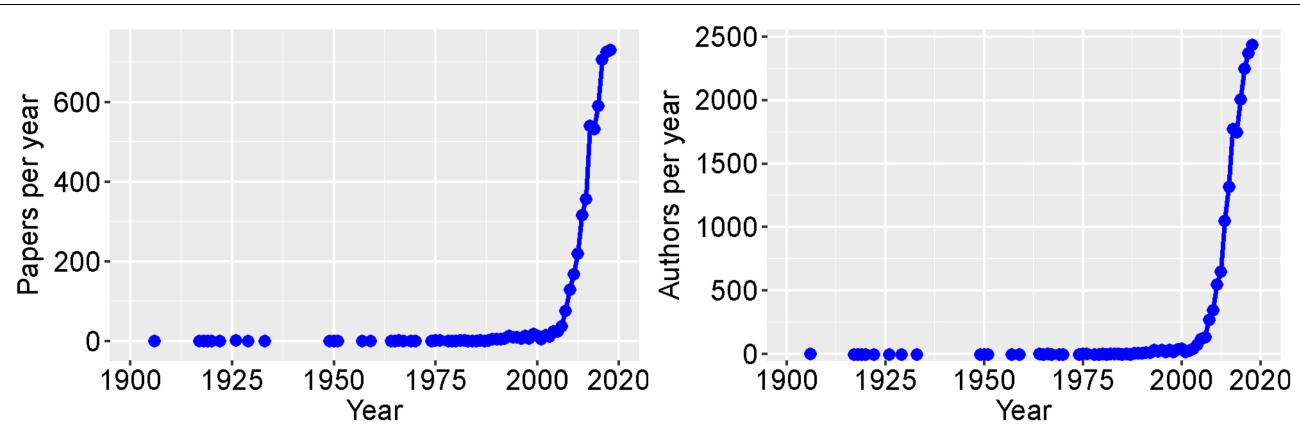

FIGURE 1 | Annual number of peer-reviewed publications on ocean acidification and number of authors involved during the period 1900-2018. Figure produced by Jean-Pierre Gattuso using the bibliographic database of the IAEA Ocean Acidification International Coordination Centre (OA-ICC).

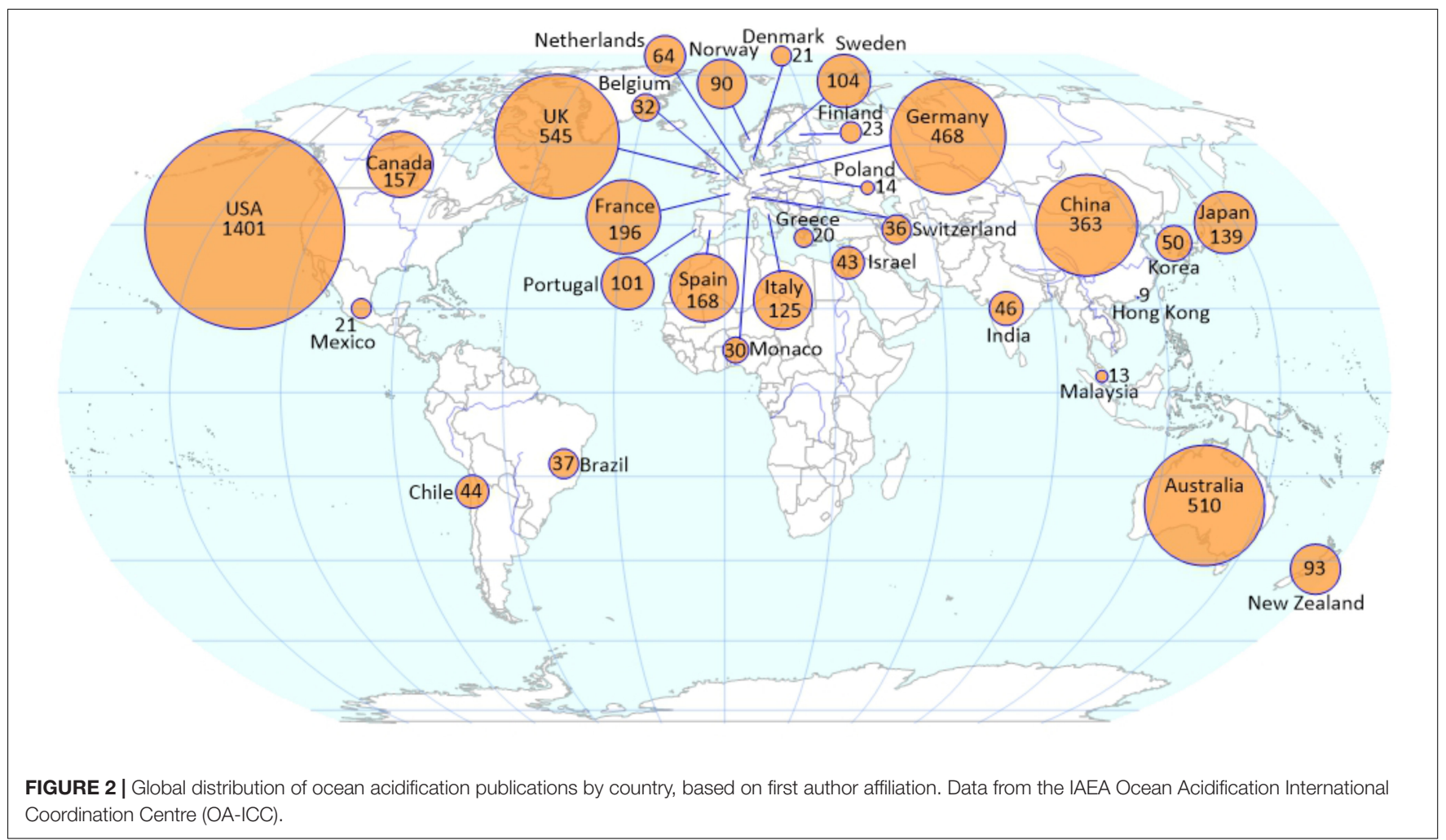

changes expected from global earth system model projections, potentially altering the ecological consequences for shelf systems.

In addition to variability in time, the rates of uptake of $\mathrm{CO}_{2}$ from the atmosphere also vary spatially, especially in coastal and shelf seas (Fennel et al., 2018; Laruelle et al., 2018). The magnitude of the sink of carbon has been shown to vary latitudinally, with high latitude (north of $30^{\circ}$ ) coastal seas providing a sink while low latitude shelves are generally a source or neutral (Cai et al., 2006; Bauer et al., 2013; Chen et al., 2013). Spatial and temporal variability poses a challenge to the observational and modeling communities that could be better addressed with new tools and sensors, capabilities and technologies (see Next Generation Sensor Technologies to Enhance the Observing System), and through international collaborative efforts like GOA-ON. The scientific challenges that the coastal variability imparts on stakeholders, managers, coastal communities, and other marine resource end-users poses unique challenges for attribution science, habitat shift projections, and stress response timing for vulnerable ecosystems. Below we describe some of the new tools, capabilities, and technologies available to be ported through new informational products served through GOA-ON, as well as the empowerment this global network offers coastal communities.

\section{NETWORK GENESIS AND CONTEXT}

Ocean observation, monitoring systems, and networks are designed to quantify variability and long-term changes, and to discover natural dynamics and anthropogenic impacts. The 

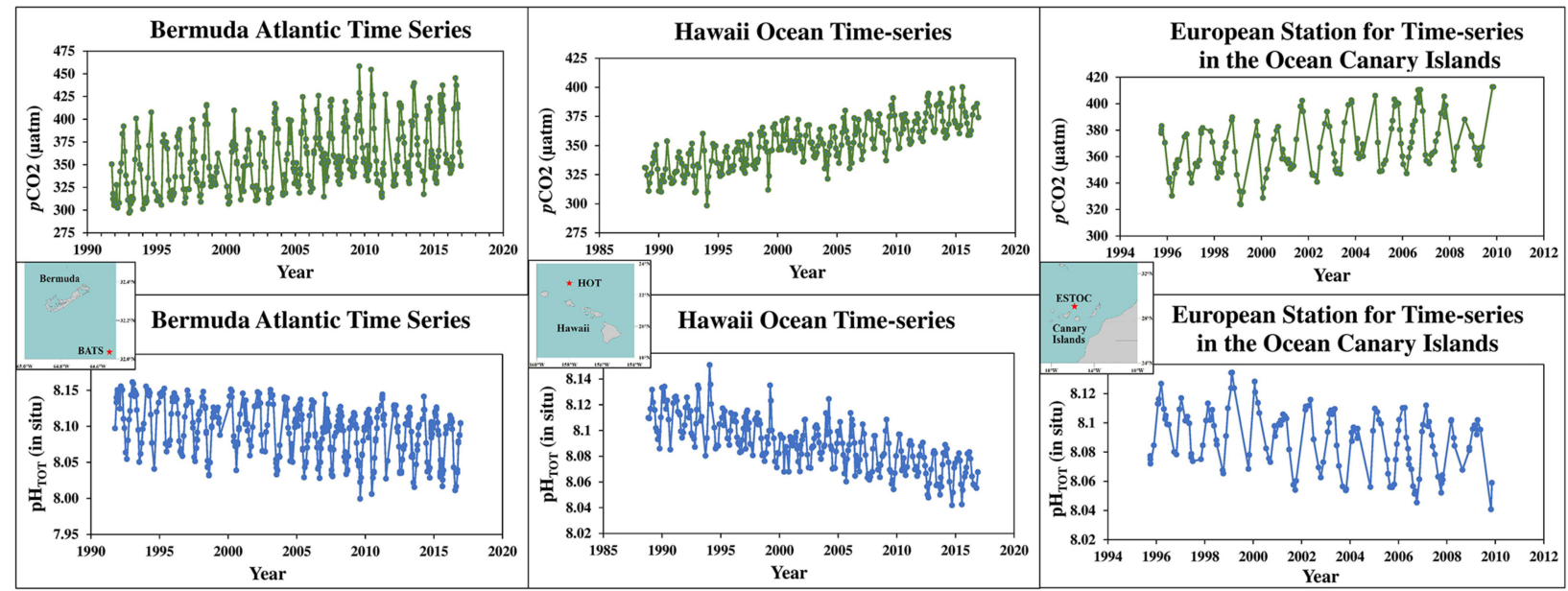

FIGURE 3 | Time series of in situ $\mathrm{pCO}_{2}$ (top) and $\mathrm{pH} \mathrm{H}_{\mathrm{T}}$ (bottom) for three time series stations in the Atlantic and Pacific Oceans. Data sources: BATS data: http://batsftp.bios.edu/BATS/bottle/; Hot data: University of Hawaii (http://hahana.soest.hawaii.edu/hot/products/HOT_surface_CO2; ESTOC data: https://www.nodc.noaa.gov/archive/arc0051/0100064/1.1/data/0-data/).

Global Ocean Observing System (GOOS), now considered the core, community-vetted ocean observing system for guidance, utilizes the Framework for Ocean Observing to implement an integrated and sustained ocean observing system (Intergovernmental Oceanographic Commission (IOC)UNESCO, 2012). This systems approach is designed to be flexible and to adapt to evolving scientific, technological, and societal needs, helping to deliver an ocean observing system tailored to user needs and the mitigation of societal impact. Within this framework, $\mathrm{OA}$ is included as one phenomenon for inorganic carbon in the Essential Ocean Variables (EOV) suite ${ }^{1}$.

The genesis of a global OA observing network with a multidisciplinary focus can be traced to an internationally authored OceanObs'09 community white paper, An International Observational Network for Ocean Acidification (Feely et al., 2010). This paper recommended "an integrated international interdisciplinary program of ship-based hydrography, time-series moorings, floats and gliders with carbon system, $\mathrm{pH}$ and oxygen sensors, and ecological surveys to determine the large-scale changes in the properties of ocean water and the associated biological responses to OA." Following panel discussions at OceanObs'09, the groundswell of scientists interested in this effort increased and broadened in discipline and expertise. In 2012, a workshop was held in Seattle, WA, United States, to design a global OA observing network that would delineate the physical-chemical processes controlling the acidification of the oceans and their large-scale biological impacts and was aligned with the EOV process. Workshop participants defined the goals and requirements of a global OA observing network in the context of responding to societal needs.

Outcomes of the Seattle meeting were community definition of the rationale, goals, design, suite of measurement parameters,

${ }^{1}$ GOOS EOV Suite: http://www.goosocean.org/components/com_oe/oe.php? task $=$ download\&id $=35906 \&$ version $=2.0 \&$ lang $=1 \&$ format $=1$. data quality objectives, data distribution strategies, and integration with international programs (Newton et al., 2013). The rationale and design of the components and locations considered existing networks and programs and identified gaps in both open-ocean and coastal regions. The minimum suite of measurement parameters and performance metrics identified two different usage cases with the data quality objectives needed to support these: (1) "Climate" is defined as measurements of quality sufficient to assess long-term trends with a defined level of confidence. With respect to OA, climate-quality data support detection of the long-term anthropogenically driven changes in hydrographic conditions and carbon chemistry over multidecadal timescales. (2) "Weather" is defined as measurements of quality sufficient to identify relative spatial patterns and short-term variation, particularly in nearshore regions where variability is higher (Table 1). Weather-quality data support mechanistic interpretation of the ecosystem response to $\mathrm{OA}$ and understanding of local, immediate OA dynamics. The name, Global Ocean Acidification Observing Network (GOA-ON), was coined at the workshop ${ }^{2}$.

GOA-ON serves three goals to (1) improve understanding of global OA conditions; (2) improve understanding of ecosystem response to OA; and (3) acquire and exchange data and knowledge necessary to optimize modeling of $\mathrm{OA}$ and its impacts (Newton et al., 2015). Thus, GOA-ON focuses on both chemistry and biology, and through its data portal ${ }^{3}$, it provides discoverability of - and in some cases access to-data for myriad uses, including to improve forecast modeling and prediction of the future ocean.

The GOA-ON community held a second workshop in St. Andrews, United Kingdom, in 2013 to refine the vision for the structure of GOA-ON, with emphasis on defining monitoring

${ }^{2}$ GOA-ON website: https://www.goa-on.org.

${ }^{3}$ http://portal.goa-on.org/Explorer 
TABLE 1 | Recommended measurement uncertainties for climate and weather from Newton et al. (2015).

\begin{tabular}{lcc}
\hline Parameter & Climate Uncertainty & Weather Uncertainty \\
\hline $\mathrm{TCO}_{2}$ & $2 \mu \mathrm{mol} / \mathrm{kg}$ & $10 \mu \mathrm{mol} / \mathrm{kg}$ \\
$\mathrm{TA}$ & $2 \mu \mathrm{mol} / \mathrm{kg}$ & $10 \mu \mathrm{mol} / \mathrm{kg}$ \\
$\mathrm{pCO}_{2}$ & $2 \mu \mathrm{atm}$ & $10 \mu \mathrm{atm}$ \\
$\mathrm{pH}$ & 0.003 & 0.02 \\
Aragonite Saturation & 0.04 & 0.2 \\
Calcite Saturation & 0.06 & 0.3 \\
\hline
\end{tabular}

for ecosystem impacts of OA in shelf and coastal seas (Newton et al., 2013). After this workshop, the development of a data portal commenced to provide OA-relevant asset locations and metadata, with a vision toward serving data products. The portal was made possible through an initial investment by the University of Washington and by leveraging existing capacity funded by the United States Integrated Ocean Observing System (U.S. IOOS). GOA-ON reached out to its members to populate the data portal, housed at the GOA-ON website, with their observing information.

At a third workshop in Hobart, Australia, in 2016, major outcomes were related to the building and reinforcement of communities to increase regional coordination, with identification of regional implementation needs, including information, data products, and capacity building. The GOA-ON mentorship program known as "Pier2Peer" (described below) was launched at this workshop. Regional OA networks, acting as regional hubs of GOA-ON, have emerged in Latin America, Africa, the Western Pacific, Europe, the South Pacific Islands, and North America. Advances have been made in capacity building, and the GOA-ON community has expanded to more than 600 members from 94 countries as of March 2019 (Figure 4). A fourth workshop in April 2019 in Hangzhou, China, targeted further development of a coordinated network and regional engagement. Workshop themes covered were ocean and coastal acidification in a multi-stressor environment; observing ocean and coastal acidification and impacts on ecosystems; modeling and forecasting ocean and coastal acidification and ecosystem responses; and focusing GOA-ON efforts for societal benefit, stakeholder needs, and capacity building.

The vision for the future of the global OA observing network, described in this white paper, is built around eight components: (1) Optimize GOA-ON to better inform modeling community needs; (2) Fill gaps in understanding of chemical changes and biological impacts; (3) Promote and advise the development of next generation sensor technology; (4) Support the growth of regional hubs and grassroots establishment of new hubs; (5) Expand and enhance capacity-building efforts to enable broader participation; (6) Improve the GOA-ON data portal; (7) Build OA networks producing scientific data and information designed to inform regional and international environmental action; and (8) Enhance collaboration with other observing networks.

\section{GOA-ON REQUIREMENTS AND GOVERNANCE}

Ocean acidification is a global issue, but it has local effects that differ depending on the environment (e.g., sensitivity of local species), and societal uses of the ocean and its resources. An approach that coordinates effort, so that global as well as local status could be assessed effectively and with consistent methods, was deemed necessary during the initial workshops held by GOAON. The OA data quality definition of Climate and Weather, based on data application, was an important step for GOA-ON. Many international or local climate assessments require climate quality data both in the open ocean and coastal seas (Karl et al., 2010). The inherent variability in coastal areas results in more

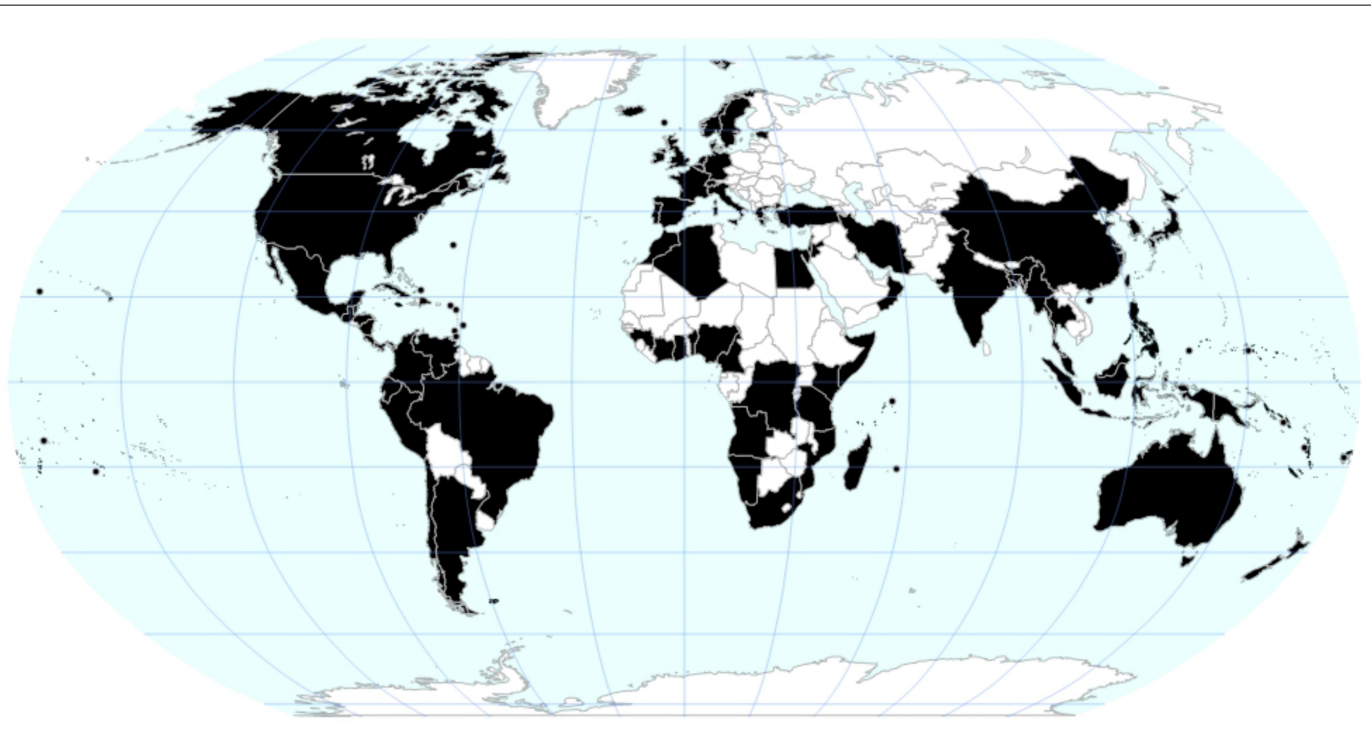

FIGURE 4 | Countries with GOA-ON members as of April 2019 are shaded black, excluding representatives of UN bodies. 
years of climate-quality data being required to observe trends (Sutton et al., 2018) compared to the open ocean. Uses such as monitoring for aquaculture and biological experiments, or for interpretations of local mechanisms underlying temporal and spatial variation can be served by either weather-quality data or climate-quality data.

Three levels of measurements were defined for the two observational goals, with level 1 being critical measurements, level 2 enhanced measurements that allow further understanding, and level 3 those in development or experimental measurements. In general, it was much easier for the community to define requirements for goal 1, OA status, than for goal 2, ecosystem response. For the latter, the participants considered diverse environments, such as polar, temperate, tropical, nearshore, and coral habitats.

Goal 1 level 1 variables are: temperature, salinity, oxygen, depth, and carbon-system constraints. Carbon-system constraints are achievable in a number of ways, including combinations of direct measurements and estimates based on measurements of at least two carbon-system variables. Two further variables, fluorescence and irradiance, were considered important, except where the platform is not appropriate or available for such measurements. Goal 2 variables provide additional detail, and the "level" requirements are defined by usage. In general, these include the goal 1 variables named above, plus variables describing phytoplankton, zooplankton, benthic producers and consumers in shelf seas and nearshore, nutrients, organic carbon and nitrogen, and microbial measures.

The outcome from the GOA-ON vision and plan is to enable globally accessible high-quality data and data synthesis products that facilitate research and new knowledge on OA, communicate the status of $\mathrm{OA}$ and biological response, and enable forecasting of OA conditions. End-uses of these data include support for the development of national and international policy and adaptive action, including those related to carbon emission policies, food security and livelihoods, fisheries and shellfish aquaculture practices, protection of coral reefs, shore protection, cultural identity, and tourism. However, investment in capacity in multiple areas critical to meet these needs must be addressed, including physical observing infrastructure, operations and maintenance, data $\mathrm{QA} / \mathrm{QC}$, analytical and synthesis activities, and the intellectual infrastructure.

Since the launch of the Global Ocean Acidification Observing Network in 2013, forward momentum has been maintained by an Executive Council of experts from around the world who either represent core scientific disciplines or international or national institutions with a leadership role in the network. A distributed secretariat was established in 2018 with support from the International Atomic Energy Agency, the Intergovernmental Oceanographic Commission, and the U.S. National Oceanic and Atmospheric Administration (NOAA) Ocean Acidification Program. The secretariat has a key role in the development of GOA-ON through the coordination and communication of activities and in building science-policy linkages. The data portal and website services are also part of the distributed secretariat, supported by NOAA's Ocean Acidification Program, U.S. IOOS, and the University of Washington.

\section{STATUS OF THE OBSERVING NETWORK}

The observing network cataloged and guided by GOA-ON represents a multinational coordination effort to harmonize ocean observing strategies aimed toward acquiring robust evidence on $\mathrm{OA}$ and its worldwide impacts, guiding management action from regional to international levels, and informing policy decisions. Participating scientists adhere closely to the established observing requirements detailed in the GOA-ON Requirements and Governance document (Newton et al., 2015), which is oriented around the three goals outlined in Section "Network Genesis and Context" of this paper. In accordance with these requirements, the existing observing network is composed of assets deployed across multiple ecosystem domains ranging from large-scale open-ocean regions to coastal environments inclusive of large estuaries and embayments. Assets deployed by GOA-ON participants are located in ecosystems as divergent as the Arctic pelagic seas to tropical coral reefs and use of a broad range of asset types from ship-based sampling to diver collection teams. Perhaps the most unique aspect of the GOA-ON observing network is the emphasis on interdisciplinary observations including carbon chemistry, meteorology, oceanography, biogeochemistry, ecology, and biology. The goal is not only to track OA, but also to understand and monitor the ecological changes that may result, and this sets GOA-ON apart from many other observing systems.

One example of this transdisciplinary approach is the strategy employed in coral reef monitoring. NOAA established a coordinated national coral reef monitoring strategy that includes a broad suite of OA-relevant ecological metrics, including the adoption of standardized Calcium Carbonate Accretion (CCA) and bioerosion indices, which are deployed in tandem with regular carbonate chemistry monitoring $\left(\mathrm{pCO}_{2 \text { sea }}, \mathrm{pCO}_{2 \text { air }}\right.$, and $\mathrm{pH}$ ) together with temperature, salinity, oxygen, fluorescence, and turbidity. The protocols and methods adopted by NOAA for coral reef $\mathrm{OA}$ monitoring have since been shared with the international community through a series of workshops that have fostered the adoption of similar methods throughout Western Pacific nations and elsewhere.

The current GOA-ON observing network ${ }^{4}$ is composed of 598 assets deployed around the world and supported by 54 nations. The assets include 247 ship-based time series, 151 moorings, 118 fixed ocean time series, 30 repeat hydrography lines, and 22 volunteer observing ships (Figure 5). However, only about two thirds of the reported assets include dual measures of the carbonate system, which is a necessary minimum prerequisite for fully constraining the system as called for under the GOA-ON requirements. Only about $30 \%$ of the assets on the portal have associated links to open-access data.

Many of the assets are deployed in specific open-ocean locations and along coastal and shelf margins that are likely to be heavily impacted by coastal biogeochemical processes. This makes direct detection of OA more challenging, particularly in the absence of suitable regionally scaled biogeochemical models that can be used for ascribing the specific drivers behind

\footnotetext{
${ }^{4}$ http://portal.goa-on.org/Explorer
} 


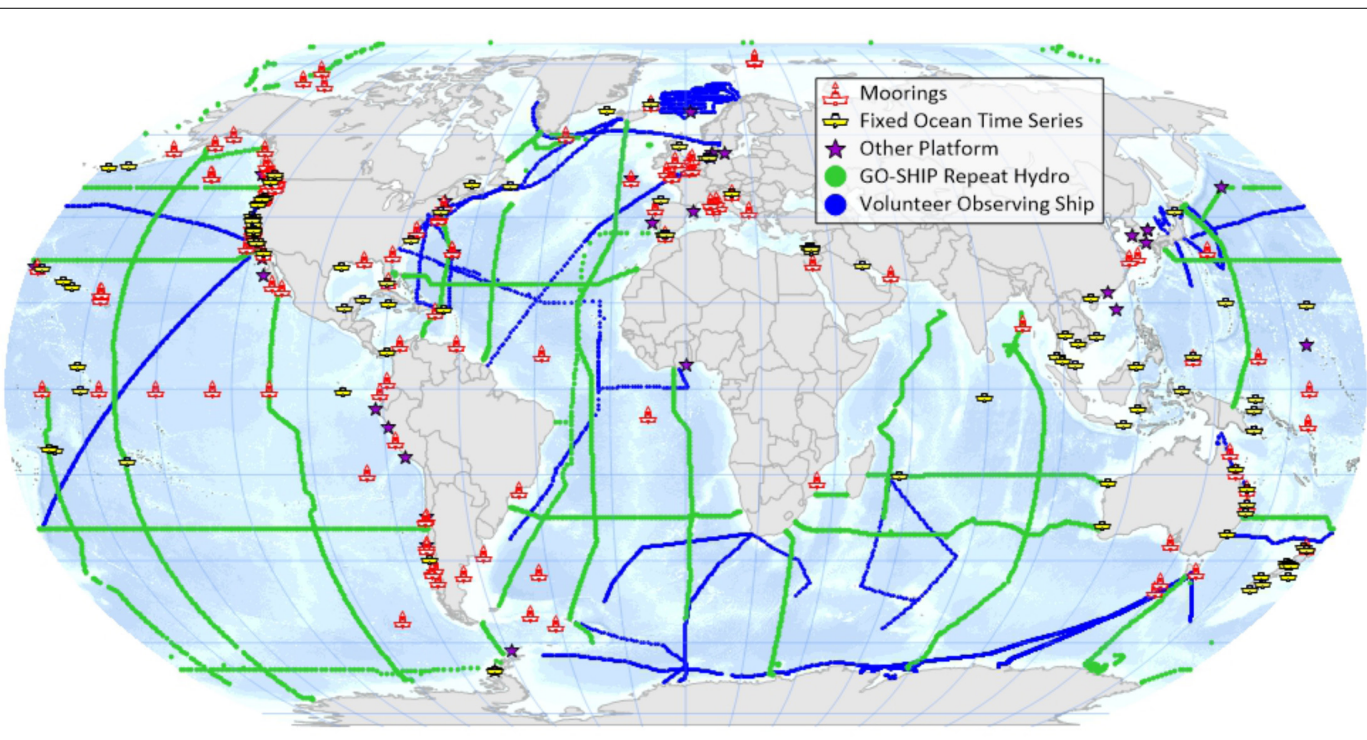

FIGURE 5 | Present-day (as of April 2019) Global Ocean Acidification Observing Network which is collaborative with the GO-SHIP, Ocean SITES, SOCONET, SOOP communities and other open-ocean and coastal observing networks.

the observed carbonate dynamics. Furthermore, many of the impacted harvestable marine species reside below the mixed layer depth while most of the observing system data to date are from the surface waters due to limited availability of sensors suitable for deep-water deployment.

The observing design is working increasingly toward collecting biological data from the field to determine if impacts predicted based on laboratory experiments are occurring in the natural environment. This includes the use of standardized CCA accretion plates in the field to determine if CCA rate changes identified in experiments are occurring in coral reefs. Almost half of the assets currently listed on the GOA-ON portal are measuring at least one biological variable (chlorophyll, cyanobacteria/bacteria, zooplankton, and/or phytoplankton). New monitoring indices such as pteropod shell condition are also being explored using repeated ship-surveys along the U.S West Coast. The identification of additional biological variables and integration into the network through cooperation with existing biological observing programs is discussed in the following section.

\section{A VISION FOR THE OCEAN ACIDIFICATION OBSERVING NETWORK}

The observing network should be optimally configured to meet modeling community needs and be fit to purpose. As detailed in the GOA-ON requirements (Newton et al., 2015), the purpose can include detection of $\mathrm{OA}$, whereby assets should be deployed where anticipated time of emergence (ToE) of an OA signal above background natural variability occurs within a few decades in terms of biogeochemical changes, and within perhaps several decades in the case of ecological monitoring (Sutton et al., 2018). This detection requires "climate-quality" data, which involves a more stringent accuracy and precision than may be needed for some applications (Table 1). Models can also assist with determining this metric as long as the primary processes driving the carbonate dynamics are suitably constrained. A well validated or data-assimilated model can be used to extend observations into the past and future. Global-scale models have been used to predict the ToE of an OA signal against the background of other environmental changes (e.g., Gruber, 2011; Carter et al., 2016, 2017; Henson et al., 2017; McKinley et al., 2017). High-resolution coastal models that connect large-scale open-ocean conditions with changes in coastal regions, including coastal upwelling and coral reef systems, are beginning to emerge (e.g., Mongin et al., 2016; Siedlecki et al., 2016; Turi et al., 2016).

In locations where the purpose of an OA observing asset is to monitor current conditions, the less stringent "weatherquality" constraints (Table 1) may meet requirements. The observing asset in this case should include a suite of observations that can adequately characterize biogeochemical OA conditions most relevant to applications such as near-real-time support of industry products. Examples include observing systems deployed at shellfish hatcheries at a number of facilities in the U.S. Northwest and Northeast (Barton et al., 2015). This level of data is often available in near-real-time, making it a vital part of forecast evaluation and a key locus of interaction with stakeholders in coastal communities.

Additionally, non-sustained deployments should be considered in cases where heuristic algorithm development or mechanistic determinations are the aim. Observing initiatives designated for the purpose of characterizing the primary modes of variability and characterizing it by means of algorithm development and constraint can prove very valuable in scaling direct observations in both time and space. Examples might include flux and rate measurements such as at the benthic interface or investigating mechanisms of predictability to enable 
forecast system development, perhaps by exploring the ways in which large-scale climate variability is communicated to regional waters and watersheds.

Observing technologies are becoming more autonomous and highly resolved in time and space, which allows observing networks to become better connected with the coasts and thus communities impacted by the changing ocean. The design and implementation of networks require them to be adaptable, so they are able to continue to evolve with emerging technologies as they become available. Coastal communities will be increasingly affected by changing ocean conditions and forecasts and real-time data access will enable them to develop strategies to respond. The co-location of chemical and biological measurements is needed to assess in situ impacts and helps build the capacity to develop indices, metrics, and risk assessment for coastal ecosystems (Boyd et al., 2015; Bednaršek et al., 2016). The same observing infrastructure should also provide or coordinate with measures of other stressors including temperature change, hypoxia, and pollution that can amplify or attenuate $\mathrm{OA}$ responses and influence the physiology, ecology, and the adaptive capacity of marine organisms (Hurd et al., 2018).

\section{Next Generation Sensor Technologies to Enhance the Observing System}

The GOA-ON goal of improving our understanding of global OA conditions will be strongly supported by the development of new sensor technology. Specifically, new technology is needed to quantify (1) the range of natural variability in diverse marine ecosystems (e.g., Figure 6) (Harris et al., 2013); (2) the organismal response to different biogeochemical conditions (Boyd et al., 2015); and (3) long-term trends in biogeochemical parameters. A wide range of in situ measurements are desired but those focused on stressors, i.e., temperature, $p \mathrm{CO}_{2}$, inorganic carbon and $\mathrm{pH}$, oxygen, nutrients, salinity (Breitburg et al., 2015), and biology (biomass, populations) (McQuillan and Robidart, 2017) are high priorities, as discussed in Section "GOA-ON Requirements and Governance." Accordingly, 10 years ago, OceanObs'09 papers (Borges et al., 2010; Byrne et al., 2010; Feely et al., 2010) called for the development of autonomous sensors and systems to quantify dissolved inorganic carbon (DIC) and total alkalinity (TA). There has been significant progress in this direction with successful in situ deployments of novel DIC and TA instruments (Spaulding et al., 2014; Fassbender et al., 2015; Wang et al., 2015). However, as stated in Byrne et al. (2010), "There are at least two principal impediments to widespread utilization of in situ instrumentation: cost and complexity." These challenges remain and have limited the widespread use of the new devices.

Moreover, even for technologies that have been on the market for several years, data quality varies substantially based on the experience level of the operators (McLaughlin et al., 2017). Continued opportunities for hands-on training, a task that is often initiated by scientists themselves, will be necessary for high-quality data collection and widespread use of new and complex devices. Co-deployment with independent sensors is recommended for new technologies (Bresnahan et al., 2014;
McLaughlin et al., 2017), further increasing the cost of obtaining high-quality data.

Sensor drift, or loss of accuracy over time, is also a persistent problem. Even when accuracy requirements are relaxed, e.g., for weather quality data in a hatchery, confidence within a defined tolerance must be established. Ideally, sensor data should be validated with independent, in situ samples. Often, conventional methods based on bottle samples collected before and after deployment do not provide sufficient replicates to confidently constrain sensor accuracy. Two highly advanced and widely utilized sensors use innovative strategies to correct for drift. Optode-based $\mathrm{O}_{2}$ sensors, a technology that is considered to be mature, have been calibrated by exposing the sensors directly to air (Bittig and Körtzinger, 2015; Bushinsky et al., 2016). ISFETbased $\mathrm{pH}$ sensors use deep-water $\mathrm{pH}$ values as a $\mathrm{pH}$ standard for drift correction (Johnson et al., 2017; Williams et al., 2017). Without these drift corrections for $\mathrm{O}_{2}$ and $\mathrm{pH}$, the measurements would not be able to quantify the small seasonal changes in open ocean environments.

Simplified technology may be on the horizon. Promising new sensors for $\mathrm{pH}$ and $\mathrm{pCO}_{2}$ are being developed based on optode time-resolved fluorescence technology similar to $\mathrm{O}_{2}$ optodes (Clarke et al., 2015, 2017). Inexpensive, low-power infrared $\mathrm{CO}_{2}$ sensors are now being used for oceanographic applications (Bastviken et al., 2015; Hunt et al., 2017). A miniature electrochemical sensor for combined measurements of $\mathrm{pH}$ and TA has recently been demonstrated (Briggs et al., 2017).

Deployment platforms are more sophisticated and able to accommodate a wider array of sensor technologies (Riser et al., 2018). Profilers include free drifting subsurface floats (Mignot et al., 2018), biogeochemical Argo profilers (Williams et al., 2017, 2018), ice-tethered (wire climbing) profilers (Toole et al., 2011), and moored profilers (e.g., winch operated; Palevsky and Nicholson, 2018). Autonomous underwater gliders and vehicles, self-propelled surface gliders such as Saildrone, and free-floating surface drifters are also becoming more common for oceanographic research in regions not readily accessible by research ships (Lindstrom et al., 2017). Cabled networks with power and high bandwidth data transmission might also become more common in the future. The adaptation of existing sensor technology to more diverse platforms is likely to continue to advance GOA-ON objectives. One additional area that is likely to improve is in our handling of big data sets, both in terms of quality control and the ability to provide real-time diagnostics (Duarte et al., 2018).

While it is likely that we will be able to more readily quantify the inorganic carbon system in the coming decade, other important parameters remain out of reach. Dissolved and particulate organic carbon are two critical pieces of the carbon cycle that might be affected by OA (Egea et al., 2018). Optical measurements (fluorescence, absorption) of colored dissolved organic matter are useful proxies (e.g., Jørgensen et al., 2011), but a direct measurement of dissolved organic carbon (DOC) that can be applied to a wide range of marine environments is needed.

A major objective of GOA-ON is to quantify relationships between marine organisms and stressors. While most research on biological impacts of ocean change is based on IPCC 


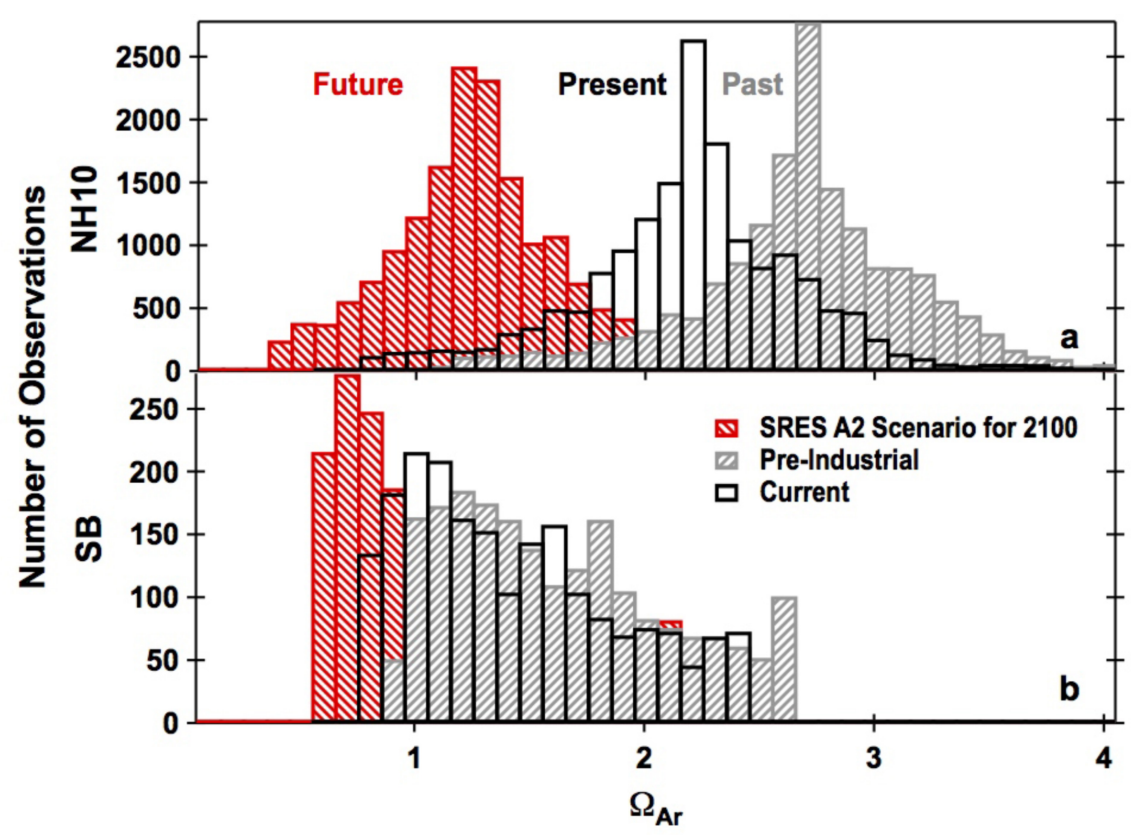

FIGURE 6 | (Top) Distribution of aragonite saturation data (open bars) calculated from in situ pH and pCO $\mathrm{pC}_{2}$ measurements collected over 5 years at the Newport Hydrographic Line mooring ( $\mathrm{NH}-10)$ off the Oregon coast (United States). The gray and red bars represent estimates from these data using pre-industrial and future $\mathrm{CO}_{2}$ levels. (Bottom) The saturation states at the Oregon shelf break at $116 \mathrm{~m}$ depth. Adapted from Harris et al. (2013).

predictions, new sensor technology reveals existing spatiotemporal complexity of the marine environment that often exceeds the envelope of predicted change (Harris et al., 2013). The variability can influence species responses to baseline changes (Boyd et al., 2016). In addition, and particularly regarding marine benthic organisms, seawater physics and chemistry may significantly vary across small microclimates within habitats. Deployment of arrays of multiple sensors may help characterize these systems (e.g., Leary et al., 2017). Combining sensor data with biology remains an important but very young area of research, and often requires interdisciplinary collaborations or advanced training. New in situ sensor technology might make this more feasible. Future exciting opportunities exist to combine biogeochemical and physical measurements with sophisticated autonomous bio-analytical systems that can characterize and quantify microbial populations (e.g., automated flow cytometry, Hunter-Cevera et al., 2016; in situ genetic analysis, McQuillan and Robidart, 2017). These approaches can potentially overcome the challenge of connecting species biomass or composition with environmental variables by continuously monitoring over a wide range of conditions (Marrec et al., 2018).

The discussion above poignantly reveals the challenges we face in developing new biogeochemical and biological sensors. Repeated "technological revolutions" have made us believe that technology will continue to advance indefinitely. Sensor transduction mechanisms, e.g., optical or electrochemical transduction, are mature. Most oceanographic sensors have utilized building blocks from other areas (e.g., fiber optics, integrated circuits) in a combinatorial evolution (Arthur, 2009) to make oceanographic sensors. New building blocks from material science, molecular biology, miniaturization, and fluidics are likely (e.g., Briggs et al., 2017) but will there be new transduction mechanisms that we do not know of today?

\section{Filling Gaps in Understanding of Biological Impacts}

Addressing $\mathrm{OA}$ to minimize impacts requires the development of a mechanistic understanding of biological effects. In turn, understanding shifts in ocean biodiversity due to global change requires inclusion of "ocean weather" such as daily and seasonal variability in ocean chemistry, including changes in that variability due to OA (Bates et al., 2018). GOA-ON's second goal calls for a greater understanding of biological impacts and strong coordination of this research. Reviewing the requirements for biological observations as outlined in Newton et al. (2015), and bridging present and future variability in the carbonate system with ecosystem changes are the objectives of the GOAON biology working group. This group works toward three main tasks:

\section{Task 1: Inform the Chemical Monitoring Program About the Biological Needs}

Marine organisms are often living in highly fluctuating environmental conditions and experience an even wider variability through migrations, changes of environment at different life-history stages or manipulation of their niche. Through local adaptation, species and ecosystems are often able to survive the wide range of variability while stress is induced in conditions deviating from present environmental conditions (Vargas et al., 2017). We need to better capture all the aspects of 
this variability; for example, predicting organism sensitivity and identifying relevant future scenarios important for determining appropriate laboratory treatments require capturing the yearly $\mathrm{pH}$ regime experienced by an organism, including extremes, such as the minimum value experienced.

\section{Task 2: Evaluate the Needs and Requirements of a Biological Monitoring Program}

Identifying which biological variables to track as indicators of OA impact is extremely challenging. Traditional biological monitoring programs tend to focus on identifying, counting, or weighing particular taxa or communities (Bednaršek et al., 2014; Gattuso et al., 2015). As the identity of these organisms and the subsequent structure of communities differs greatly from place to place, it is difficult to identify key marine species or community types that can be monitored everywhere. Instead, the GOA-ON biology working group is aiming to identify ecosystemlevel indicators that are likely to be impacted by OA, such as biogeochemical biomarkers of acidification and other stressors.

\section{Task 3: Develop a Theoretical Framework Linking Chemical Changes to Biological Response}

Forecasting biological impacts is one of the most pressing and important challenges in the field of OA. An understanding of what is driving biological responses to $\mathrm{OA}$ is critical as input to biological and ecological models that allow us to expand from existing monitoring initiatives to a more comprehensive biological response understanding. Using existing literature and a theoretical framework such as the niche theory, the GOA-ON biology working group is developing a probabilistic approach aimed at identifying the species, ecosystems, and sites that are the most at risk.

\section{COORDINATION AMONG OCEAN OBSERVING NETWORKS}

The existing large-scale oceanic carbon observatory network of the Global Ocean Ship-based Hydrographic Investigations Program (GO-SHIP) surveys, the Surface Ocean $\mathrm{CO}_{2}$ Observing Network (SOCONET), the Ship of Opportunity Program (SOOP) volunteer observing ships, and the Ocean Sustained Interdisciplinary Time-series Environment observation System (OceanSITES) time-series stations in the Atlantic, Pacific, and Indian Oceans have provided a backbone of observations of the carbonate chemistry needed to address the problem of OA. These activities are linked through the International Ocean Carbon Coordination Project. Much of our present understanding of the long-term changes in the carbonate system is derived from these repeat surveys and time series measurements in the open ocean (Feely et al., 2004; Sabine et al., 2004; Carter et al., 2017; Williams et al., 2017). Enhancing these activities and expanding the global time-series network with new carbon and $\mathrm{pH}$ sensors, particularly in the Southern Hemisphere, is providing important information on the changing conditions in both open-ocean and coastal environments that have been extensively under-sampled in the past. At present, many of the existing moored carbon observatories only measure $\mathrm{pCO}_{2}$ in surface waters, which is of itself insufficient to constrain the carbon system adequately for effective monitoring and forecasting $\mathrm{OA}$ conditions and the concomitant biological effects. Future efforts will require additional observations with an enhanced suite of physical, chemical, and biological sensors in the ocean.

The GOA-ON has been designed to be fully integrated and collaborative with other large-scale ocean carbon observing networks cited above by enhancing these networks with additional measurement capabilities, including additional sensors, data assimilation and distribution of resources via the GOA-ON data portal and linking them with coastal observing networks that also address OA. The resulting network design is coordinated to link existing efforts with a common resources, infrastructure, data, and modeling capabilities (Figure 5).

GO-SHIP plans are being augmented to include full water column and underway $\mathrm{pH}$ measurements on every cruise (Sloyan et al., in review). Plans for further expansion include the addition of biological and bio-optical measurements for estimating primary production, carbon export, and species changes. The SOCONET and SOOP networks, including volunteer observing ships and moorings, are also being expanded to include $\mathrm{pH}$ and other carbon system parameters where practical (Wanninkhof et al., in review), and many OceanSITES moorings have been outfitted with $\mathrm{pH}, \mathrm{pCO}_{2}$, and other biogeochemical sensors. Data integration, validation, and dissemination will continue to be implemented through the Surface Ocean $\mathrm{CO}_{2}$ Atlas (SOCAT), the GLobal Ocean Data Analysis Project (GLODAP), and GOAON data portals.

Biological observations addressing the impact of OA ought to be framed within existing efforts, such as the Marine Biodiversity Observation Network (MBON). The Group on Earth Observations and $\mathrm{MBON}$ have worked together to define Essential Biodiversity Variables and GOOS has developed 'Biology and Ecosystem' Essential Ocean Variables (Miloslavich et al., 2018; Muller-Karger et al., 2018). Synergistic effort among the biological and OA communities by bringing experts together to discuss a common set of core variables to gain a more consistent and informed understanding of biological responses to $\mathrm{OA}$ is encouraged. Equally important will be the joint responsibilities of capacity building, mentoring, data delivery and outreach activities similar to those implemented by GOA$\mathrm{ON}$ and partners and described in Sections "Data Access Through the Global Data Portal" and "Capacity Building and Regional Coordination."

Future plans for enhancement of the GOA-ON network include new observational time-series sites, new technologies, particularly autonomous observing platforms such as Saildrones and Biogeochemical Argo floats in both open-ocean and coastal locations, and the development of new modeling tools and data synthesis products for depicting global and regional trends in acidification and associated responses of marine food webs and ecosystems. Integration with emerging observing networks like the Global Ocean Oxygen Network will provide a global focus on understanding multiple stressor impacts and feedbacks. By combining observational capabilities wherever feasible we will 
be better positioned to provide integrated information on the combined effects of acidification and deoxygenation to scientists, stakeholders and the interested public.

\section{DATA ACCESS THROUGH THE GLOBAL DATA PORTAL}

The GOA-ON data portal provides an overview of where and how $\mathrm{OA}$ is measured and provides capability to access and visualize data and synthesis products. The inventory of assets can be searched interactively by region, platform type and variables, and observation-based products include contoured worldwide data such as $\mathrm{pH}$, aragonite saturation, and total $\mathrm{CO}_{2}$ from GLODAP and annual and decadal $\mathrm{CO}_{2}$-weighted fugacity from SOCAT. Icons are used to display observing assets, many of which include links to data and metadata and some display real-time data. Observing assets include both stationary platforms such as fixed time series, moorings, and mobile platforms such as repeat hydrography, ship-based time series, and volunteer observing ships. For a given carbonate chemistry-measuring asset, the metadata include information on which parameters are measured and are linked to data providers, and other details.

Open and public access to data is a central tenet for increasing OA knowledge. Many members of GOA-ON who have provided coordinates for OA data-relevant observing platforms also provide access to the data from those platforms. A significant challenge is to facilitate better access to data in regions that overlap with the Exclusive Economic Zone (EEZ) of nations that restrict data access, declaring the information too sensitive to share. These EEZ regions may be sites of large variability and change, and they are potentially high risk for OA impacts on ecosystems and populations. GOA-ON will be working to facilitate data access in all regions.

\section{Improving the Data Portal}

There are several ways to add value to how the GOA-ON Data Explorer portal visualizes products from local to global scales. For example, the Data Explorer shows calculated aragonite saturation state $(\Omega)$, a biologically relevant value, for a few of the near realtime moorings. NOAA Pacific Marine Environment Laboratory has provided interactive box plots of monthly averaged aragonite saturation and $\mathrm{pH}$, with pie charts showing the percent of time the measurements are below a given threshold value. The interactive feature of these plots allows for the $\mathrm{pH}$ or aragonite threshold to be adjusted up or down by the user. Thus, quantitative information on habitat suitability for different species with individual tolerances can be observed. This same approach can be expanded to other fixed assets with time series data. Another example is to utilize models of OA conditions that are calibrated and verified by observing data, providing regional and local forecast model output that can identify habitat suitability patterns in space and time. User confidence in the model output will be increased by a feature such as a "comparator" to compare model output and mooring data. Such a feature was developed by the U.S. IOOS' Northwest Association of Networked Ocean Observing Systems (NANOOS) ${ }^{5}$ on their Data Explorer, which can be adapted to the portal. These two suggestions are within the current capability of the portal to serve, but dependent on output from scientists who maintain and develop models and moorings. However, support to maintain and develop the models, moorings, and analyses is required and often lacking.

New products that synthesize data are needed to provide information on status and trends, summary statistics, and graphics that are suitable for managers, policymakers, and the public. International buy-in and creative development are core needs for the portal development. GOA-ON envisions its data portal to be serving rather than archiving data, and to leverage and collaborate with the International Oceanographic Data and Information Exchange (IODE), National Oceanographic Data Centres (NODCs), and international data holdings, applying the metadata and data formats developed for the UN SDG 14.3.1 reporting process (discussed in more detail in Section "2030 Agenda") and other national and regional data centers. The visualization of 14.3.1 data provided by UN member states via the GOA-ON portal will be a direct service to scientists, policymakers and stakeholders.

During the next decade it will be necessary to develop tools and mechanisms to illustrate current and projected impacts of OA on marine life (GOA-ON Goal 2). Collaborative efforts between GOA-ON, GOOS, and subject-specific efforts such as the Ocean Biogeographic Information System (OBIS) and Intergovernmental Oceanographic Commission (IOC) Working Group 'International Group for Marine Ecological Time Series' (IGMETS), can be used to collect related data and information. Interoperability so that synthesis products can pull in both chemical and biological data is imperative. Producing such tools and visualization products will take substantial effort but doing so is at the heart of what society and scientists need; a way to easily view $\mathrm{OA}$ and ecosystem response.

\section{CAPACITY BUILDING AND REGIONAL COORDINATION}

Building capacity is essential to fill gaps in regions where there are few observations and research on OA, but where OA could have major consequences for livelihoods. Training courses focusing on resource-limited countries have been organized through collaboration among GOA-ON, the International Atomic Energy Agency's Ocean Acidification International Coordination Centre (IAEA OA-ICC), the US-based non-profit The Ocean Foundation, the Intergovernmental Oceanographic Commission of UNESCO (IOC-UNESCO), and partners from the scientific community, local and regional stakeholders. Over 40 capacity building opportunities held since 2012 have trained over 480 researchers from 69 countries (Figure 7). The opportunities have ranged from training courses to regional coordination workshops, to support for participation in international conferences. The training courses have varied

\footnotetext{
${ }^{5}$ www.nanoos.org; Data Explorer: http://nvs.nanoos.org/.
} 


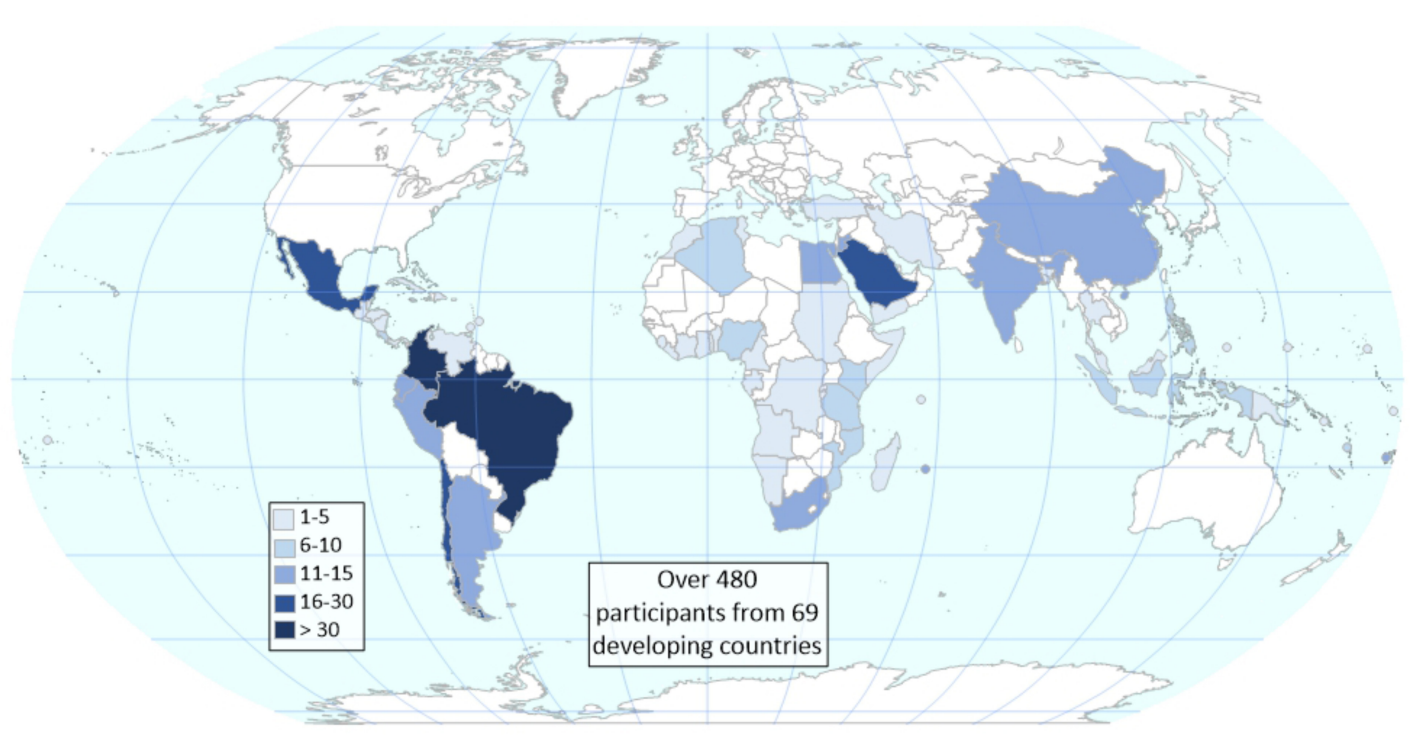

FIGURE 7 | Location and number of participants from developing countries involved in OA training workshops from 2012 to 2018.

in focus (e.g., chemistry, biology, data management) and level (basic to more advanced) depending on regional needs and have been adjusted in response to feedback from participants from early courses. Additional resources have also been developed [e.g., databases ${ }^{6}$, 'Best practices' documents, online discussion fora $\left(\mathrm{OAIE}^{7}\right)$, e-learning tools, etc.] to reach a wider audience and for sustaining OA research after the courses.

The lack of availability of instrumentation has hampered the establishment of sustained measurements for many countries and research organizations. In response, simplified methods and kits of equipment to measure weather-quality $\mathrm{pH}$ and $\mathrm{TA}$, known as 'GOA-ON in a Box's have been developed', with The Ocean Foundation providing kits to fifteen countries in Africa, the Pacific Small Island Developing States and the Caribbean.

GOA-ON also launched the Pier2Peer mentorship program in 2016 to facilitate one-on-one collaborations through direct transfer of expertise and advice by matching experienced researchers with early career researchers. Pier2Peer includes 93 mentees from 50 countries and 62 mentors from 15 countries. Although the program does not have dedicated funding, it has benefitted from a scholarship program organized by The Ocean Foundation $^{10}$, which has provided some funding for training visits and the establishment of new monitoring programs. The mentoring process has helped develop close working relationships between early career researchers and experts from

\footnotetext{
${ }^{6} \mathrm{OA}-\mathrm{ICC}$ databases: https://www.iaea.org/services/oa-icc/science-andcollaboration/data-access-and-management.

${ }^{7}$ The Ocean Acidification Information Exchange: https://www.oainfoexchange. org/.

${ }^{8}$ https://www.oainfoexchange.org/teams/GOA-ON-Community

${ }^{9}$ https://news-oceanacidification-icc.org/2016/10/21/iaea-int7019-task-forcemeeting-on-the-development-and-standardization-of-methodology-12-14october-monaco/

${ }^{10} \mathrm{https} / / /$ www.oceanfdn.org/projects/hosted-projects/ocean-acidification
}

many institutions, and the feedback on small grants applications associated with the Pier2Peer program has been an effective way to encourage better grant writing skills.

\section{A Vision for Enhancing and Expanding Capacity Building}

Capacity building, including training, mentorship, and providing access to equipment is a priority for the GOA-ON community in recognition of the strong disparity among scientific capabilities across the globe. Tracking how global capacity changes over time will be critical, especially to know whether scientists in resource challenged countries are able to maintain monitoring over time with their respective country's support (Figure 8).

Future fundraising strategies will rely on an ongoing communications effort that showcases both the power of a global network and the uses for local data. The resources raised might support both regional trainings, including data management, and new scientific projects advanced through Pier2Peer proposals.

Beyond maintenance and improvement of fundraising and institutional support, the strategy for capacity building operations in the next decade will focus on enhancing the network and the direct exchange of expertise and technology at national, regional, and global levels. The facilitation of direct interaction with established scientific experts through workshops and mentorships has been one of the most successful components of GOA-ON, and it is relatively low-cost. Encouraging collaboration and exchange of knowledge between peers as well as experts has also been highly successful and will continue to be a cornerstone of capacity building.

The establishment of regional centers of excellence for sample analyses and training are possibilities, including the development of more advanced training in data quality control to ensure highquality data sets are made available through publicly accessible platforms and eLearning resources. Equally important is the 


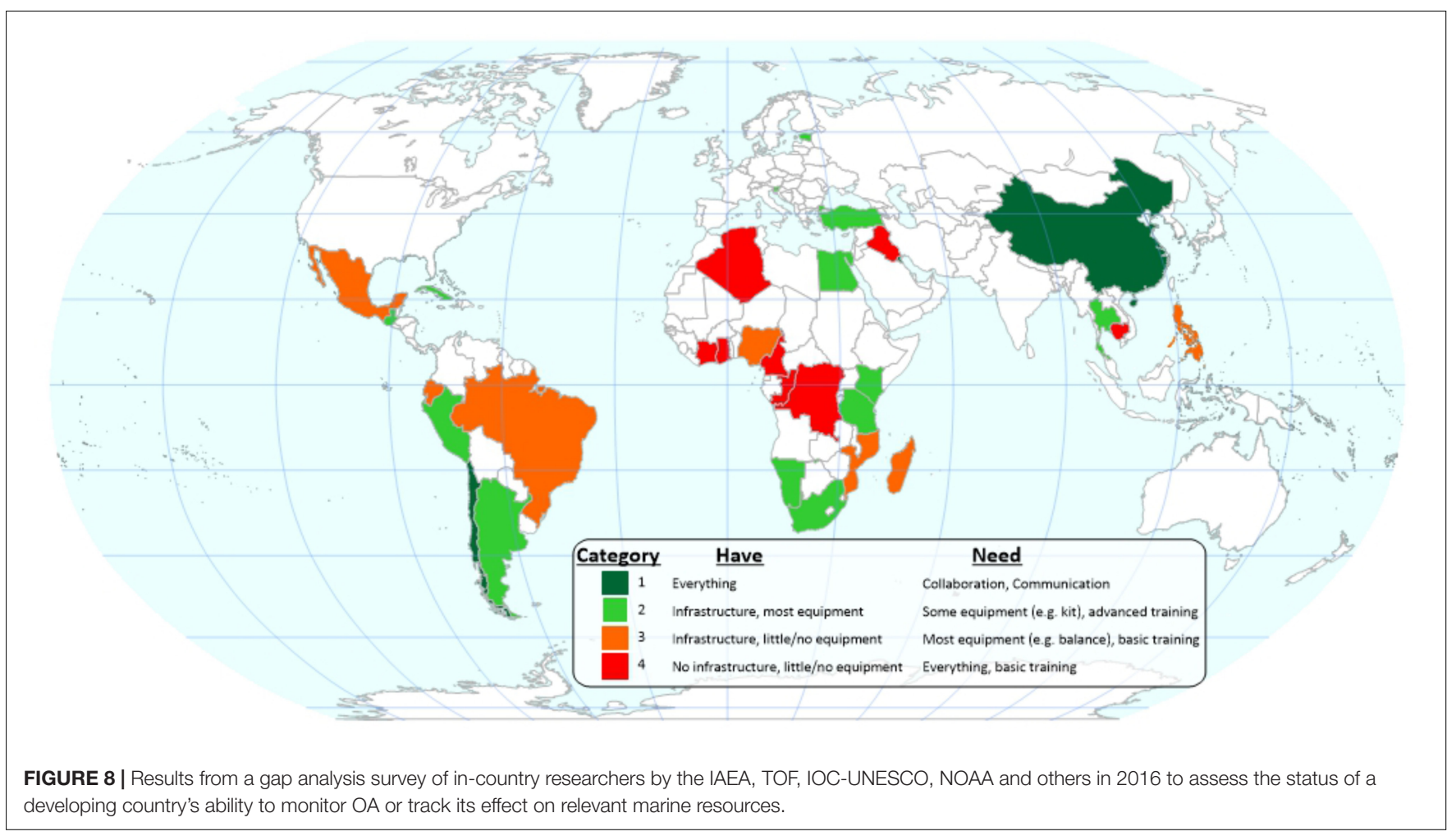

identification of data-serving platforms (or proposals to create new ones) so that every scientist, regardless of country, has an online repository for serving of data.

Capacity building and training workshops have also identified a number of technical challenges to address. The development of low-cost and simple-to-use equipment, such as handheld spectrophotometric $\mathrm{pH}$ analyzers, will be essential for the ongoing success of this work. The sustainable production of certified reference materials covering a range of salinities from estuaries to the open ocean and the provision of purified $\mathrm{pH}$ indicator dyes that are affordable and accessible are common requirements for the community.

The demand for training from developing countries and access to appropriate technology is expected to increase in the next decade as many countries begin to report toward SDG 14.3.1, which is discussed in detail in Section "2030 Agenda." GOAON's role in coordinating and providing capacity building will be increasingly important to make sure that limited resources are used in the best way possible. Periodic assessment through surveys of both the effectiveness and long-term sustainability of these efforts, which were initiated with regional and/or international funds, will rely on networks like GOA-ON.

\section{The Importance and Future Role of Regional Hubs}

Regional networks or "hubs" are an essential component of GOAON's operating structure because they allow for geographicallyspecific coordination and local expertise to address needs and gaps in $\mathrm{OA}$ monitoring. The hubs are formed in a grassroots manner and are self-governing with GOA-ON providing advice and support and a representative of each hub serves on the Executive Council. Seven hubs are currently providing opportunities for regional networking, collaboration, training, and the identification of region-specific priorities and scientific gaps: LAOCA ${ }^{11}$, the IOC-WESTPAC OA Program ${ }^{12}$, the OAAfrica Network ${ }^{13}$, and the North American Ocean Acidification Network $^{14}$, the Pacific Islands and Territories Ocean Acidification network (PI-TOA) ${ }^{15}$, Northeast Atlantic ${ }^{16}$, and Mediterranean hubs $^{17}$.

Two priority areas for future hubs are the Arctic and Southern Oceans. These are regions where biological impacts due to OA may already be occurring (Kawaguchi et al., 2013; Bednaršek et al., 2016; Rastrick et al., 2018) and the skill of models in predicting changes are least certain (Lenton et al., 2013; Kwiatkowski and Orr, 2018).

Regional hubs will continue to be essential for meeting future needs for GOA-ON's three goals. Local and regional collaboration is easier to maintain logistically, encourages collaboration among scientists studying the same or adjacent ocean and coastal systems, and coordinates localized knowledge of potential socioeconomic impacts. OA is progressing differently across various coastal areas and regions; therefore, it is important

\footnotetext{
${ }^{11}$ http://laoca.cl/en/

${ }^{12} \mathrm{http} / / /$ iocwestpac.org/oa/870.html

${ }^{13}$ https://www.oa-africa.net/

${ }^{14}$ http://goa-on.org/regional_hubs/north_america/about/introduction.php

${ }^{15}$ http://goa-on.org/regional_hubs/pitoa/about/introduction.php

${ }^{16}$ https://www.pml.ac.uk/Research/Projects/North_East_Atlantic_hub_of_the Global_Ocean_Acidif

${ }^{17}$ http://goa-on.org/regional_hubs/mediterranean/about/introduction.php
} 
to have geographically localized coordination that is largely independent of a more global approach.

The GOA-ON Executive Council will continue to ensure representation of the hubs on the global stage and maintain a grassroots approach to the formation and governance of each hub. Beyond this, priorities for the regional hubs from the perspective of the GOA-ON Executive Council include: (1) continued support and capacity building where possible; (2) increased scientific collaboration within and between the hubs; (3) increased sharing of best practices among hubs and between the GOA-ON Executive Council and the hubs; (4) enhanced communication between the hubs and the GOA-ON Executive Council on capacity-building needs and opportunities; and (5) the bottom-up formation of more hubs to create global coverage on a regional scale.

\section{The Latin American Ocean Acidification Network (LAOCA): Status and Vision of the First Hub}

LAOCA was the first regional hub formed by GOA-ON members. The LAOCA Network was officially established in December 2015 during the 1st Latin American Workshop on Acidification of the Oceans in Concepcion, Chile. Representatives from Argentina, Brazil, Chile, Colombia, Ecuador, Mexico, and Peru founded the Network. At this first meeting, the members of the LAOCA network stressed the importance of biodiversity in Latin American ecosystems and their willingness to cooperate and to share the information. The first LAOCA Symposium for the members was held in October 2017 in Buenos Aires, Argentina, with the addition of Costa Rica as a new member. This meeting was a unique opportunity to share results about OA observation and research in the region and emphasized the potential of ongoing and future research to address common challenges.

The LAOCA research strategies include:

(i) The study of the carbonate system in coastal, oceanic, and estuarine waters, and its ecological and biogeochemical implications;

(ii) The experimental evaluation of the biological responses of marine organisms to future scenarios of $\mathrm{OA}$ and interaction with other climatic and anthropogenic stressors;

(iii) Modeling and projection of local and regional scenarios of OA for Latin America based on monitoring at high spatial and temporal resolution; and

(iv) The effect on socio-ecological systems of the participating countries.

Over the past years, Latin American scientists have identified the need to develop an observing strategy for monitoring fisheries, biodiversity, environmental variability and ecosystem management at their coasts, considering the different levels of observing capacity. Complementary experimental research is needed to improve knowledge about ecosystem and species adaptation potential and the predictive capability of models. Additionally, LAOCA members have identified the need to quantify and improve our understanding of the changes and, in particular, the consequences of OA on ocean and human health, to develop mitigation and adaptation strategies for society. The challenge is to improve communication with stakeholders and help make the best and boldest decisions. One key aspect is advocating the issue of $\mathrm{OA}$ on the political agenda for the different countries that take part in the LAOCA network.

At a regional symposium in Santa Marta, Colombia, in March 2018, several priorities were identified that are associated with technical regional standardization, accessibility to equipment and facilities, data and model availability, assertive communication at different levels, and policy relevance and recognition. Common regional data storage and sharing facilities have also been identified as important to foster increased collaboration and harmonization of methods that will increase visibility and best communicate the challenges and implications associated with OA.

The vision for the next 10 years is to facilitate working across the region and expand participation to all countries with coastal zones, convening scientists from different disciplines in order to advance knowledge about OA, its quantification, and its consequences at local and regional levels. LAOCA will continue sharing knowledge through courses to train early-career scientists from the Latin American and Caribbean regions entering the OA field. Finally, LAOCA needs to be a platform to engage with particular stakeholder's needs such as the aquaculture industry, artisanal fisheries or managers seeking environmental solutions.

\section{BROADER INTERGOVERNMENTAL CONSTRUCTS FOR OA ACTION}

Like many other environmental problems, OA is a transboundary problem. While the top five countries for $\mathrm{CO}_{2}$ emissions are China, the United States, India, Russia, and Japan (JanssensMaenhout et al., 2017), model results show that the Arctic and Antarctic oceans, and the upwelling ocean waters off the west coasts of North America, South America, and Africa are especially vulnerable to OA (Jiang et al., 2015). In other words, the top emitters are not necessarily the countries experiencing the worst effects from OA, which creates a disconnect between actions and impacts.

Many of the countries that will experience the worst impacts of OA are those with limited scientific and technical expertise needed to establish monitoring efforts. Global observing networks such as GOA-ON are key mechanisms to support countries in building scientific capacity. They are also key to provide international organizations, such as IOC-UNESCO, with technical advice to improve the political framework to enable scientific and observational knowledge generation needed to combat the impacts of OA. GOA-ON has been explicitly noted in several intergovernmental fora as an exemplar of international scientific collaboration.

The assessment of international policy and governance options addressing $\mathrm{OA}$ has highlighted the fragmented and insufficient political preparedness for mitigating the effects of OA on marine ecosystems and ecosystem services (Herr et al., 2014). Since then, the 2030 Agenda, the UN Framework Convention on 
Climate Change (UNFCCC) with its Paris Agreement and the related Marrakesh Global Climate Action Platform on Oceans and Coastal Areas, and the Global Climate Observing System have provided the political rationale to foster and expand $\mathrm{OA}$ research and observation through networks like GOA-ON.

Additionally, past developments addressing adaptation to OA have emphasized the need to identify how OA will alter marine life and the ocean economy in the next decade. This will allow the advancement of global and site-specific adaptation strategies and increase the resilience of coastal communities (e.g., Hennige et al., 2014; International Council for the Exploration of the Sea (ICES), 2014). The outcome is expected to feed back into conventions and agreements, such as the Convention on Biological Diversity, the adaptation options within the UNFCCC, and regional fisheries bodies.

\section{Fisheries and Aquaculture, Coral Reef Protection and Tourism, and Other OA-Affected Societal Resources and Their Stakeholders}

Ocean acidification effects on many societally relevant issues, like fisheries, aquaculture, coral reef protection and tourism are locally diverse, but need to be globally considered. For example, a globally recognized but localized impact is the plight of Pacific Northwest U.S. shellfish growers who found their natural sets of oysters and their ability to grow shellfish larvae in hatcheries was reduced in the early to mid-2000s (Barton et al., 2015). The combination of coastal upwelling of $\mathrm{CO}_{2}$-rich waters with the anthropogenic $\mathrm{CO}_{2}$ uptake tilted aragonite saturation states to low values that impacted the oysters. For now, active monitoring, seawater buffering, and other adaptation practices have alleviated this issue for the hatcheries, but this example serves as a call to action to connect the science to society, especially with respect to $\mathrm{OA}$ and fisheries and aquaculture. Globally, the multiple stressors of $\mathrm{OA}$, rising temperatures, hypoxia, and harmful algal blooms will conspire to affect coastal fisheries and aquaculture industries upon which many individuals, cultures, and nations depend. The new Food and Agriculture Organization of the United Nations synthesis volume on "Impacts of climate change on fisheries and aquaculture" outlines impacts, vulnerabilities, and adaptations for marine fisheries in regional seas and focuses on the need for methods and tools for adaptation (Barange et al., 2018). Close collaboration of GOA-ON with fisheries and aquaculture is a critical area for growth and focused attention in the coming decade.

Coral reefs affect coastal economies and ecology in disproportionate ways. While coral reefs cover only $0.16 \%$ of the sea surface, they host about $30 \%$ of all known marine species and are essential to about 500 million people, generating at least \$300-400 billion per year in terms of food and livelihoods from tourism, fisheries, coastal protection and medicines. A recent workshop organized by the Centre Scientifique de Monaco and the IAEA OA-ICC identified nine common solutions for six major coral reef regions and individual localized solutions for each of the diverse reef systems (Hilmi et al., 2018). These examples emphasize the need for a coordinated
OA observation network that is relevant to both local and global scales and one that is integrated nimbly across these scales. Local lessons learned and the most efficacious observing strategies to enable adaptation are best shared globally by intentional coordination.

\section{Agenda}

Within the UN 2030 Agenda, the aim of SDG 14 is to "conserve and sustainably use the oceans, seas, and marine resources," and consists of 10 targets. GOA-ON supports countries to achieve Target 14.3, which aims to "minimize and address the impacts of OA, including through scientific cooperation at all levels." The progress made toward this target by all UN Member States is measured by the corresponding indicator 14.3.1 "Average marine acidity $(\mathrm{pH})$ measured at agreed suite of representative sampling stations." IOC-UNESCO is the custodian agency for this indicator and was tasked to develop an indicator methodology (Intergovernmental Oceanographic Commission (IOC)-UNESCO, 2018 $)^{18}$. GOA-ON provided expert-level input into the methodology, which provides detailed guidance to scientists and countries in terms of what to measure, and how to follow best practice guidelines established by the OA community. It also includes recommendations on how to report and openly share the collected information in a manner that ensures it is transparent, traceable, and useable for global comparison of $\mathrm{pH}$ measurements. Through this process, GOAON directly contributes to the achievement of SDG Target 14.3. The collective expertise of GOA-ON in science and policy ensures the development of a guiding vision for the collection and sharing of ocean chemistry data, which in the future is envisaged to extend to biological data. The development of the 14.3.1 methodology is the first step in this process.

A streamlined reporting mechanism to obtain a comprehensive $\mathrm{OA}$ data set on an annual basis via connecting data providers and different types of data repositories is a main objective of the SDG 14.3.1 methodology. IODE-associated NODCs and Associated Data Units were surveyed in 2018 about the biogeochemical data they hosted, including which of the four carbonate chemistry parameters $\left(\mathrm{pH}, \mathrm{TA}, \mathrm{DIC}, \mathrm{CO}_{2}\right)$ they served. More than $50 \%$ of these data centers were found to not serve any OA data, which might be due to no active OA observation in the region/country, limited capacity by the respective NODCs to hold this kind of information, or that scientists are directly submitting relevant data to international and/or regional data centers, such as PANGAEA ${ }^{19}$ and the Integrated Carbon Observation System ${ }^{20}$. A newly developed 14.3.1 Ocean Acidification Data portal to be launched in 2019 to assist in achieving the full implementation of the 14.3.1 methodology and increasing the capacity of countries to share data.

The 2030 Agenda framework provides many ways to support GOA-ON goal 1 (Figure 9). Voluntary Commitments are initiatives undertaken by Governments, the United Nations

\footnotetext{
${ }^{18}$ See IOC/EC-LI/2 Annex 6 http://unesdoc.unesco.org/images/0026/002651/ 265127e.pdf.

${ }^{19}$ https://www.pangaea.de/

${ }^{20}$ https://www.icos-ri.eu/
} 


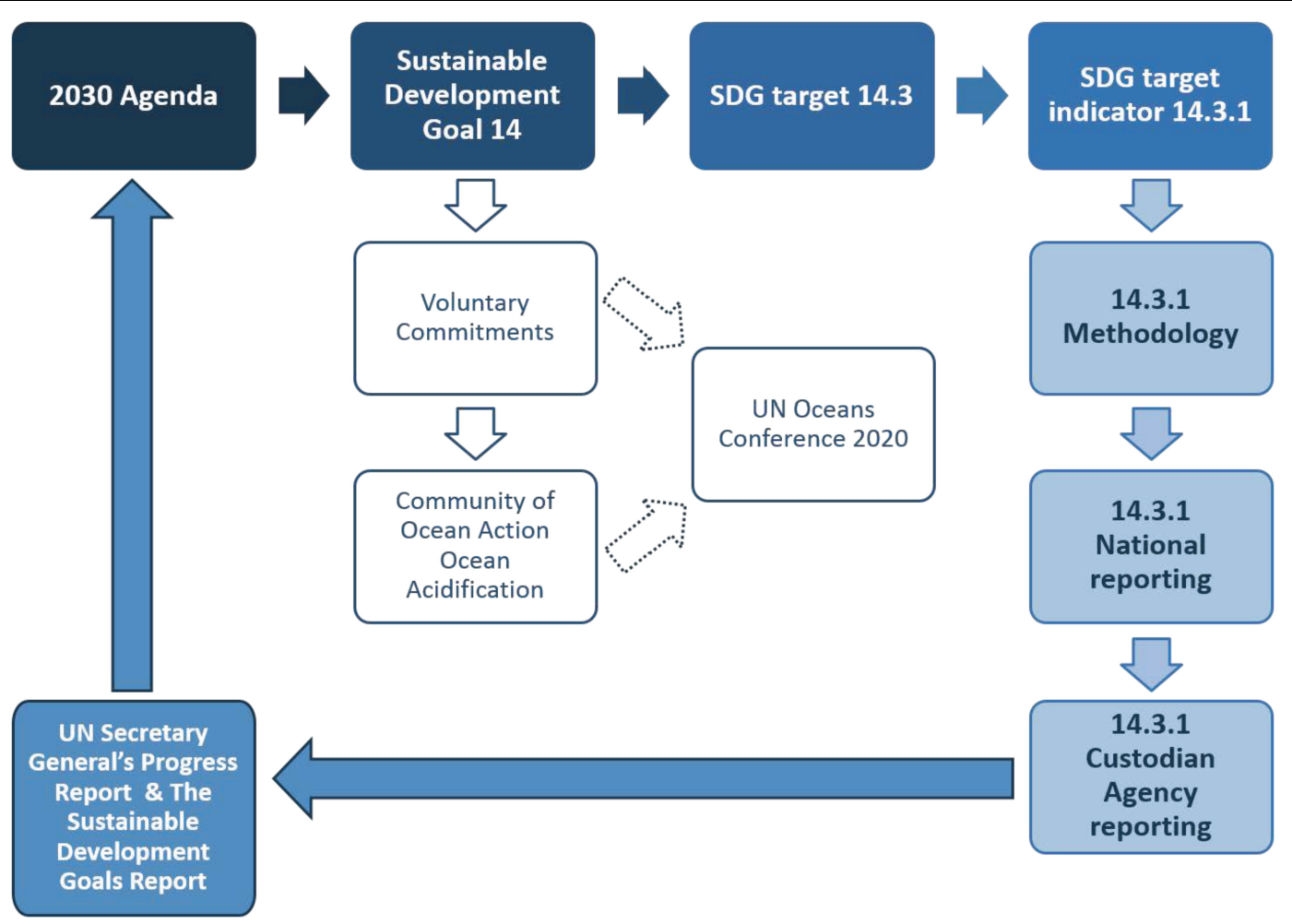

FIGURE 9 | Scheme illustrating the pathways for input to the 2030 Agenda for ocean acidification observations.

system, other intergovernmental organizations, international and regional financial institutions, non-governmental organizations and civil society organizations, academic and research institutions, the scientific community, the private sector, philanthropic organizations and other actors-individually or in partnership - that aim to contribute to the implementation of SDG 14. There are currently 247 Voluntary Commitments that address $\mathrm{OA}$, and 61 are of direct relevance to it. The Voluntary Commitments are organized in a Community of Ocean Action. GOA-ON submitted a Voluntary Commitment (\#OceanAction16542) ${ }^{21}$, which includes support for measuring OA, storage, and data visualization by 2020 . However, these deliverables will only be accomplished with continuous and increasing financial commitment by countries and organizations to establish and sustain OA observations. The UN Ocean Conference 2020 will be the time to assess achievements from Voluntary Commitments and how to proceed.

\section{UN Framework Convention on Climate Change}

Ocean acidification gained further recognition through its adoption as a Global Climate Indicator in 2018. The Global Climate Indicators are a suite of seven parameters, presented to the UNFCCC, that describe the changing climate in an effort to recognize impacts beyond temperature change. The Indicators include atmospheric composition, energy, ocean, water and the

\footnotetext{
${ }^{21} \mathrm{https} / / /$ oceanconference.un.org/commitments/?id=16542
}

cryosphere. The inclusion of OA in this list shows the importance of guidance to achieve global alignment in observing OA as provided in the SDG target indicator 14.3.1 methodology.

\section{CONCLUSION}

On a global scale, the building blocks of an integrated OA network in the open ocean are well established and quality-control mechanisms are in place (e.g., Climate and Ocean: Variability, Predictability, and Change [CLIVAR]/GOSHIP, OceanSITES, SOCONET, SOOP, SOCAT). However, early consensus of the GOA-ON community is that there is a substantial need for increased observation in many coastal areas, particularly in upwelling regions, regions strongly influenced by freshwater, and coral reef environments (Newton et al., 2015). Components of the open ocean system, including the Southern Hemisphere oceans and the polar seas of the Arctic and Antarctic, are poorly sampled and need enhancement through the application of new technology and optimal use of ships and other observing platforms in the region.

For shelf seas and coasts, a global network for assessment of $\mathrm{OA}$ is under construction as a high priority for GOA-ON. At the regional level, there are some systems in place with ability to leverage OA observations on existing infrastructure (e.g., World Association of Marine Stations, International Long-Term Ecological Research Network), although many gaps remain. These elements need a globally consistent design, 
which must also be coordinated and implemented on a regional scale. The Regional Hubs of GOA-ON provide the people-to-people foundation for enhancement of these coastal observations, ensuring that data collected can answer regionally relevant questions.

In the coming decade, the GOA-ON will be a critical resource for meeting the SDG 14.3 target, to "minimize and address the impacts of $\mathrm{OA}$, including through enhanced scientific cooperation at all levels" through expert advice and by facilitating the provision of data to support the associated indicator. Building the capacity of countries to submit data to this indicator will be a guiding priority for the GOA-ON Executive Council in the coming years. By facilitating the collection of data in support of SDG 14.3, GOA-ON contributes to the sustainable use of the ocean envisioned by the 2030 Agenda. In addition, a focus on developing better, more reliable, easy to use, and hopefully lowercost technologies for data collection of existing and newly vetted parameters, both autonomously and handheld, will support these SDG efforts.

The UN has proclaimed a Decade of Ocean Science for Sustainable Development (2021-2030) to support efforts to reverse the cycle of decline in ocean health and gather ocean stakeholders worldwide behind a common framework, which will ensure ocean science can fully support countries in creating improved conditions for sustainable development of the Ocean. Ocean Science-research and observation-focusing on the impact of multiple stressors on the marine ecosystems, including OA, will be at the heart of the Decade. GOA-ON's activities will be important stepping stones to develop the mitigation and adaptation strategies for sustainable management of ocean resources. Improving the current knowledge on how OA affects ocean economy is essential to predict the consequences of change, design mitigation, and guide adaptation.

Significant progress has been made in the past decade to foster an integrated, leveraged approach to tracking and understanding OA through direct observation. The GOA-ON, a cornerstone of this broader effort, will work to move the community forward to realize this collective vision.

\section{Recommendations}

- Coordination among scientists from a range of disciplines (from chemistry to biology to technology development) and from across the globe including developing regions, particularly by:

- co-locating chemical and biological measurements to build capacity to develop indices, metrics, and risk assessments;

- articulating needed biological metrics to chemical monitoring programs;

- collaboratively evaluating the needs and requirements of a global biological monitoring program; and

o developing a theoretical framework linking chemical changes to biological responses.

- Government, private, and United Nations support for OA observing efforts;
- Develop and enhance regional cohorts working together on regionally specific OA issues;

- Make observational data from the open ocean to coastal to estuarine systems publicly accessible as much as possible;

- Develop capacity so that countries have expertise and guidance needed to report OA data as part of the Sustainable Development Goal 14.3.1 process;

- Promote even closer integration between the Global OA Observing Network and other ocean observing networks focusing on related measurements or issues toward this shared vision;

- Produce observation-based informational products useful for decision making, such as developing tools and mechanisms to visualize the impacts of OA on marine life;

- Optimize the observing system to better support modeling community needs, especially for coastal systems;

- New networks should consider prioritizing the following when considering the future of their OA observing networks:

o to support monitoring that can contribute to Time of Emergence calculations, some data sets acquired should be from the same location, similar time window, and of "climate quality";

○ to support forecasting and model development, some observations should be prioritized to be real-time or near-real-time;

- targeted observing initiatives designated for the purpose of characterizing the primary modes of variability that include subsurface observations;

- co-located physical, chemical, and biological observations to assist in co-stressor and attribution research.

- Encourage research to fill gaps in understanding of the biological, ecological, and socioeconomic impacts of OA, particularly by enhanced research on the impacts and interactions of multiple stressors on marine ecosystems;

- Promote the development of next generation sensor technology, particularly new technology that enhances ability to quantify:

o the range of natural variability in diverse marine ecosystems; and

○ the organismal response to different biogeochemical conditions;

- long-term trends in biogeochemical parameters.

- Expand and enhance capacity building efforts to enable broader participation in OA observing and research through:

- continued growth and support of scientific mentorship activities;

- further development of regional centers of excellence which can host ongoing trainings and analyze water samples; 
- provision of advanced trainings that include lessons on data quality control and quality assurance;

o identification and development of accessible, sustainable data hosting platforms; and

- periodic assessment of global, regional, and local capacity to conduct $\mathrm{OA}$ research.

\section{AUTHOR CONTRIBUTIONS}

BT, EJ, MD, JH-A, RF, DKG, LH, KI, MK, JN, SS, and FC contributed to the conception and design of the manuscript and provided text that served as the foundation for the manuscript development. BT, EJ, RF, and JN led the review, the design, and the development of the manuscript, with much assistance from ML, SD, DG, ML, MD, EC, and LK. CP, MG, KS, and MT gathered and incorporated larger community input for the manuscript. All authors contributed to the manuscript revision and have read and approved the submitted version.

\section{FUNDING}

The secretariat support provided by the IOC-UNESCO, the International Atomic Energy Agency, and the NOAA Ocean Acidification Program (OAP) is central to the GOAON effort. GOA-ON also acknowledges NOAA OAP, the University of Washington, U.S. IOOS, and NANOOS for support of the GOA-ON data portal and website, and The Ocean Foundation and government agencies for capacity building and training support. The Climate Science Centre of CSIRO Oceans and Atmosphere and the Integrated Marine Observing System funded the contribution of BT. EJ, RF, DKG, MK, and DG were funded by the NOAA Ocean Acidification

\section{REFERENCES}

Albright, R., Caldeira, L., Hosfelt, J., Kwiatkowski, L., Maclaren, J. K., Mason, B. M., et al. (2016). Reversal of ocean acidification enhances net coral reef calcification. Nature 531, 362-365. doi: 10.1038/nature1 7155

Arthur, W. B. (2009). The Nature of Technology: What it is and How it Evolves. New York, NY: Free Press.

Barange, M., Bahri, T., Beveridge, M., Cochrane, K., Funge-Smith, S., and Poulain, F. (eds) (2018). Impacts of Climate Change on Fisheries and Aquaculture-Synthesis of Current Knowledge, Adaptation And Mitigation Options. Rome: FAO.

Barton, A., Waldbusser, G., Feely, R., Weisberg, S., Newton, J., Hales, B., et al. (2015). Impacts of coastal acidification on the pacific northwest shellfish industry and adaptation strategies implemented in response. Oceanography 28, 146-159. doi: 10.5670/oceanog.2015.38

Bastviken, D., Sundgren, I., Natchimuthu, S., Reyier, H., and Gålfalk, M. (2015). Technical note: cost-efficient approaches to measure carbon dioxide (CO2) fluxes and concentrations in terrestrial and aquatic environments using mini loggers. Biogeosciences 12, 3849-3859. doi: 10.5194/bg-12-38492015

Bates, A. E., Helmuth, B., Burrows, M. T., Duncan, M. I., Garrabou, J., Guy-Haim, T., et al. (2018). Biologists ignore ocean weather at their peril. Nature 360, 299-301. doi: 10.1038/d41586-018-05869-5
Program. MD participation was funded by the U.S. National Science Foundation. JN thanks the University of Washington's Applied Physics Laboratory and College of the Environment, NOAA OAP, U.S. IOOS, and NANOOS, and the Washington Ocean Acidifdication Center for support for her role in this contribution. MT acknowledges support from the U.S. National Science Foundation grant OCE-1840868 to the Scientific Committee on Oceanic Research (SCOR, U.S.). KI and KS thank the Government of Germany for its financial support to the ocean acidification activities at the Intergovernmental Oceanographic Commission of UNESCO (IOC-UNESCO). LH contributions were funded by the International Atomic Energy Agency Ocean Acidification International Coordination Centre (OA-ICC), supported by several Member States via the IAEA Peaceful Uses Initiative. MK contributions were funded by the United States Department of State through an IAEA Junior Professional Officer position. The IAEA is grateful for the support provided to its Environment Laboratories by the Government of the Principality of Monaco.

\section{ACKNOWLEDGMENTS}

This community white paper was the collective work of many researchers. Over 600 members of GOA-ON, and especially the past and present members of the executive committee, have been critical to the development of an ongoing collaborative network to address ocean acidification and the goals outlined in this paper. The authors thank the two reviewers and the editor FM-K, for their insightful comments, which have improved the manuscript. The authors also thank Sandra Bigley (NOAA PMEL) for her editing assistance that greatly contributed to this manuscript. This is Contribution Number 4877 from the NOAA Pacific Marine Environmental Laboratory.

Bauer, J. E., Cai, W. J., Raymond, P. A., Bianchi, T. S., Hopkinson, C. S., and Regnier, P. A. (2013). The changing carbon cycle of the coastal ocean. Nature 504, 61-70. doi: 10.1038/nature12857

Bednaršek, N., Feely, R. A., Reum, J. C. P., Peterson, W., Menkel, J., Alin, S. R., et al. (2014). Limacina helicina shell dissolution as an indicator of declining habitat suitability due to ocean acidification in the California current ecosystem. Proc. Roy. Soc. Lond. B 281:20140123. doi: 10.1098/rspb.2014.0123

Bednaršek, N., Feely, R. A., Tolimieri, N., Hermann, A. J., Siedlecki, S. A., Waldbusser, G. G., et al. (2017). Exposure history determines pteropod vulnerability to ocean acidification along the US West Coast. Sci. Rep. 7:4526. doi: 10.1038/s41598-017-03934-z

Bednaršek, N., Harvey, C. J., Kaplan, I. C., Feely, R. A., and Možina, J. (2016). Pteropods on the edge: cumulative effects of ocean acidification, warming, and deoxygenation. Prog. Oceanogr. 145, 1-24. doi: 10.1016/j.pocean.2016. 04.002

Bittig, H. C., and Körtzinger, A. (2015). Tackling oxygen optode drift: near-surface and in-air oxygen optode measurements on a float provide an accurate in situ reference. J. Atmos. Ocean. Tech. 32, 1536-1543. doi: 10.1175/JTECH-D-1400162.1

Blunden, J., Arndt, D. S., and Hartfield, G. (eds) (2018). State of the climate 2017. Bull. Amer. Meteor. Soc. 99, Si-S310. doi: 10.1175/2018BAMSState oftheClimate.1

Borges, A. V., Alin, S. R., Chavez, F. P., Vlahos, P., Johnson, K. S., Holt, J. T., et al. (2010). "A global sea surface carbon observing system: inorganic and 
organic carbon dynamics in coastal oceans," in Proceedings of the OceanObs'09: Sustained Ocean Observations and Information for Society, eds J. Hall, D. E. Harrison, and D. Stammer (Venice: ESA Publication).

Boyd, P. W., Cornwall, C. E., Davison, A., Doney, S. C., Fourquez, M., Hurd, C. L., et al. (2016). Biological responses to environmental heterogeneity under future ocean conditions. Global Change Biol. 22, 2633-2650. doi: 10.1111/gcb. 13287

Boyd, P. W., Lennartz, S. T., Glover, D. M., and Doney, S. C. (2015). Biological ramifications of climate-change-mediated oceanic multi-stressors. Nat. Clim. Change 5, 71-79. doi: 10.1038/nclimate2441

Breitburg, D. L., Salisbury, J., Bernhard, J. M., Cai, W.-J., Dupont, S., Doney, S. C., et al. (2015). And on top of all that... Coping with ocean acidification in the midst of many stressors. Oceanography 28, 48-61. doi: 10.5670/oceanog. 2015.31

Bresnahan, P. J., Martz, T. R., Takeshita, Y., Johnson, K. S., and LaShomb, M. (2014). Best practices for autonomous measurement of seawater $\mathrm{pH}$ with the honeywell durafet. Methods Oceanogr. 9, 44-60. doi: 10.1016/j.mio.2014. 08.003

Briggs, E. M., Sandoval, S., Erten, A., Takeshita, Y., Kummel, A. C., and Martz, T. R. (2017). Solid state sensor for simultaneous measurement of total alkalinity and $\mathrm{pH}$ of seawater. ACS Sensors 2, 1302-1309. doi: 10.1021/acssensors.7b0 0305

Bushinsky, S., Emerson, S., Riser, S., and Swift, D. (2016). Accurate oxygen measurements on modified Argo floats using in situ air calibration. Limnol. Oceanogr. Methods 14, 451-506.

Byrne, R. H., DeGrandpre, M. D., Short, R. T., Martz, T. R., Merlivat, L., McNeil, C., et al. (2010). "Sensors and systems for in situ observations of marine carbon dioxide system variables," in Proceedings of the OceanObs'09: Sustained Ocean Observations and Information for Society, eds J. Hall, D. E. Harrison, and D. Stammer (Venice: ESA Publication).

Cai, W.-J., Dai, M., and Wang, Y. (2006). Air-sea exchange of carbon dioxide in ocean margins: a province-based synthesis. Geophys. Res. Lett. 33: L12603.

Carter, B. R., Feely, R. A., Mecking, S., Cross, J. N., MacDonald, A. M., Siedlecki, S. A., et al. (2017). Two decades of pacific anthropogenic carbon storage and ocean acidification along global Ocean Ship-based hydrographic investigations program sections P16 and P02. Global Biogeochem. Cycles 31, 306-327. doi: 10.1002/2016GB005485

Carter, B. R., Frölicher, T. L., Dunne, J. P., Rodgers, K. B., Slater, R. D., and Sarmiento, J. L. (2016). When can ocean acidification impacts be detected from decadal alkalinity measurements? Global Biogeochem. Cycles 30, 595-612. doi: 10.1002/2015GB005308

Chavez, F. P., Pennington, J. T., Michisaki, R. P., Blum, M., Chavez, G. M., Friederich, J., et al. (2017). Climate variability and change: response of a coastal ocean ecosystem. Oceanography 30, 128-145. doi: 10.5670/oceanog. 2017.429

Chen, C.-T. A., Huang, T.-H., Chen, Y.-C., Bai, Y., He, X., and Kang, Y. (2013). Airsea exchanges of CO2 in the world's coastal seas. Biogeosciences 10, 6509-6544. doi: 10.5194/bg-10-6509-2013

Clarke, J. S., Achterberg, E. P., Connelly, D. P., Schuster, U., and Mowlem, M. (2017). Developments in marine pCO2 measurement technology; towards sustained in situ observations. Trends Analyt. Chem. 88, 53-61. doi: 10.1016/j. trac.2016.12.008

Clarke, J. S., Achterberg, E. P., Rérolle, V. M. C., Kaed Bey, S., Floquet, C. F. A., and Mowlem, M. (2015). Characterisation and deployment of an immobilised $\mathrm{pH}$ sensor spot towards surface ocean pH measurements. Analyt. Chim. Acta 897, 69-80. doi: 10.1016/j.aca.2015.09.026

Doney, S. C., Fabry, V. J., Feely, R. A., and Kleypas, J. A. (2009). Ocean acidification: the other CO2 problem. Annu. Rev. Mar. Sci. 1, 169-192. doi: 10.1146/annurev. marine.010908.163834

Duarte, C. M., Poiner, I., and Gunn, J. (2018). Perspectives on a global observing system to assess ocean health. Front. Mar. Sci. 5:265. doi: 10.3389/fmars.2018. 00265

Egea, L. G., Jiménez-Ramos, R., Hernández, I., Bouma, T. J., and Brun, F. G. (2018). Effects of ocean acidification and hydrodynamic conditions on carbon metabolism and dissolved organic carbon (DOC) fluxes in seagrass populations. PLoS One 13:e0192402. doi: 10.1371/journal.pone.0192402
Eyre, B. D., Cyronak, T., Drupp, P., Heinen De Carlo, E., Sachs, J. P., and Andersson, A. (2018). Coral reefs will transition to net dissolving before end of century. Science 359, 908-911. doi: 10.1126/science.aao1118

Fabricius, K. E., De'ath, G., Noonan, S., and Uthicke, S. (2014). Ecological effects of ocean acidification and habitat complexity on reef-associated macroinvertebrate communities. Proc. R. Soc. B 281:20132479. doi: 10.1098/ rspb.2013.2479

Fassbender, A. J., Sabine, C. L., and Feifel, K. M. (2015). Consideration of coastal carbonate chemistry in understanding biological calcification. Geophys. Res. Lett. 43, 4467-4476. doi: 10.1002/2016GL068860

Feely, R. A., Fabry, V. J., Dickson, A. G., Gattuso, J.-P., Bijma, J., Riebesell, U., et al. (2010). "An international observational network for ocean acidification," in Proceedings of the OceanObs'09: Sustained Ocean Observations and Information for Society, eds J. Hall, D. E. Harrison, and D. Stammer (Venice: ESA Publication).

Feely, R. A., Sabine, C. L., Lee, K., Berelson, W., Kleypas, J., Fabry, V. J., et al. (2004). Impact of anthropogenic $\mathrm{CO} 2$ on the $\mathrm{CaCO} 3$ system in the oceans. Science 305, 362-366. doi: 10.1126/science.1097329

Feely, R. A., Wanninkhof, R., Carter, B. R., Landschützer, P., Sutton, A. J., and Triñanes, J. A. (2018). Global ocean carbon cycle. Bull. Am. Meteorol. Soc. 99, S96-S100. doi: 10.1175/2018BAMSStateoftheClimate.1

Fennel, K., Alin, S. R., Barbero, L., Evans, W., Bourgeois, T., Cooley, S., et al. (2018). Carbon cycling in the North American coastal ocean: a synthesis. Biogeosci. 16, 1281-1304. doi: 10.5194/bg-2018-420

Gattuso, J.-P., Magnan, A., Billé, R., Cheung, W. W. L., Howes, E. L., Joos, F., et al. (2015). Contrasting futures for ocean and society from different anthropogenic CO2 emissions scenarios. Science 349:aac4722. doi: 10.1126/science.aac 4722

Gruber, N. (2011). Warming up, turning sour, losing breath: ocean biogeochemistry under global change. Philos. Trans. R. Soc. A 369, 1980-1996. doi: 10.1098/rsta.2011.0003

Harris, K. E., DeGrandpre, M. D., and Hales, B. (2013). Aragonite saturation state dynamics in a coastal upwelling zone. Geophys. Res. Lett. 40, 2720-2725. doi: $10.1002 /$ grl.50460

Harvey, B. P., Agostini, S., Wada, S., Inaba, K., and Hall-Spencer, J. E. (2018). Dissolution: the Achilles' heel of the triton shell in an acidifying ocean. Front. Mar. Sci. 5:371. doi: 10.3389/fmars.2018.00371

Hennige, S., Roberts, J., and Williamson, P. (eds) (2014). An Updated Synthesis of the Impacts of Ocean Acidification on Marine Biodiversity. CBD Technical Series 75. Montreal, QC: Secretariat of the Convention on Biological Diversity.

Henson, S. A., Beaulieu, C., Ilyina, T., John, J. G., Long, M., Séférian, R., et al. (2017). Rapid emergence of climate change in environmental drivers of marine ecosystems. Nat. Commun. 8:14682. doi: 10.1038/ncomms14682

Herr, D., Isensee, K., Harrould-Kolieb, E., and Turley, C. (2014). Ocean Acidification: International Policy and Governance Options. Gland: International Union for Conservation of Nature (IUCN).

Hilmi, N., Allemand, D., Claudel-Rusin, A., Gazeau, F., Gaziello, M., Hansson, L., et al. (2018). "From sciences to solutions: ocean acidification impacts on ecosystem services-case studies on coral reefs," in Proceedings of the Fourth International Workshop on the Economics of Ocean acidification: Bridging the Gap between Ocean Acidification Impacts and Economic Valuation, (Monaco: Scientific Centre of Monaco).

Hunt, C. W., Snyder, L., Salisbury, J. E., Vandemark, D., and McDowell, W. H. (2017). SIPCO2: a simple, inexpensive surface water pCO2 sensor. Limnol. Oceanogr. Methods 15, 291-301. doi: 10.1002/lom3.10157

Hunter-Cevera, K. R., Neubert, M. G., Olson, R. J., Solow, A. R., Shalapyonok, A., and Sosik, H. M. (2016). Physiological and ecological drivers of early spring blooms of a coastal phytoplankter. Science 354, 326-329. doi: 10.1126/science. aaf8536

Hurd, C. L., Lenton, A., Tilbrook, B., and Boyd, P. W. (2018). Current understanding and challenges for oceans in a higher-CO2 world. Nat. Clim. Change 8, 686-694. doi: 10.1038/s41558-018-0211-0

Intergovernmental Oceanographic Commission (IOC)-UNESCO (2012). A Framework for Ocean Observing By the Task Team for an Integrated Framework for Sustained Ocean Observing (IFSOO). Paris: UNESCO.

Intergovernmental Oceanographic Commission (IOC)-UNESCO (2018). Update on IOC Custodianship Role in Relation. (to)SDG 14 Indicators. Paris: UNESCO. 
Intergovernmental Panel on Climate Change (IPCC) (2013). "Climate change 2013: the physical science basis," in Contribution of Working Group I to the Fifth Assessment Report of the Intergovernmental Panel on Climate Change, eds T. F. Stocker, D. Qin, G.-K. Plattner, M. Tignor, S. K. Allen, J. Boschung, et al. (Cambridge: Cambridge University Press).

International Council for the Exploration of the Sea (ICES) (2014). Final Report to OSPAR. (of)the Joint OSPAR/ICES Ocean Acidification Study Group (SGOA). Copenhagen: ICES.

Janssens-Maenhout, G., Crippa, M., Guizzardi, D., Muntean, M., Schaaf, E., Olivier, J. G. J., et al. (2017). Fossil CO2 \& GHG emissions of all world countries. JRC Science for Policy Report 107877. Luxembourg: Publications Office of the European Union.

Jiang, L. Q., Feely, R. A., Carter, B. R., Greeley, D. J., Gledhill, D. K., and Arzayus, K. M. (2015). Climatological distribution of aragonite saturation state in the global oceans. Global Biogeochem. Cycles 29, 1656-1673. doi: 10.1002/ $2015 \mathrm{gb} 005198$

Johnson, K. S., Plant, J. N., Coletti, L. J., Jannasch, H. W., Sakamoto, C. M., Riser, S. C., et al. (2017). Biogeochemical sensor performance in the SOCCOM profiling float array. J. Geophys. Res. Oceans 122, 6416-6436. doi: 10.1002/ 2017JC012838

Jørgensen, L., Stedmon, C. A., Kragh, T., Markager, S., Middelboe, M., and Søndergaard, M. (2011). Global trends in the fluorescence characteristics and distribution of marine dissolved organic matter. Mar. Chem. 126, 139-148. doi: 10.1016/j.marchem.2011.05.002

Karl, T. R., Arguez, A., Huang, B., Lawrimore, J. H., McMahon, J. R., Menne, M. J., et al. (2010). Possible artifacts of data biases in the recent global surface warming hiatus. Science 348, 1469-1472. doi: 10.1126/science.aaa5632

Kawaguchi, S., Ishida, A., King, R., Raymond, B., Waller, N., Constable, A., et al. (2013). Risk maps for Antarctic krill under projected southern ocean acidification. Nat. Clim. Change 3, 843-847. doi: 10.1038/nclimate 1937

Kroecker, K. J., Kordas, R. L., Crim, R., Hendriks, I. E., Ramajo, L., Singh, G. S., et al. (2013). Impacts of ocean acidification on marine organisms: quantifying sensitivities and interaction with warming. Global Change Biol. 19, 1884-1896. doi: $10.1111 /$ gcb.12179

Kwiatkowski, L., and Orr, J. C. (2018). Diverging seasonal extremes for ocean acidification during the twenty-first century. Nat. Clim. Change 8, 141-145. doi: 10.1038/s41558-017-0054-0

Laruelle, G. G., Cai, W.-J., Hu, X., Gruber, N., Mackenzie, F. T., and Regnier, P. (2018). Continental shelves as a variable but increasing global sink for atmospheric carbon dioxide. Nat. Commun. 9:454. doi: 10.1038/s41467-01702738-z

Le Quéré, C., Andrew, R. M., Friedlingstein, P., Sitch, S., Pongratz, J., Manning, A. C., et al. (2018). Global carbon budget 2017. Earth Syst. Sci. Data 10, 405-448. doi: 10.5194/essd-10-405-2018

Leary, P. R., Woodson, C. B., Squibb, M. E., Denny, M. W., Monismith, S. G., and Micheli, F. (2017). "Internal tide pools" prolong kelp forest hypoxic events. Limnol. Oceanogr. 62, 2864-2878. doi: 10.1002/lno.10716

Lenton, A., Tilbrook, B., Law, R., Bakker, D., Doney, S., Gruber, N., et al. (2013). Sea-air CO2 fluxes in the southern ocean for the period 1990-2009. Biogeosciences 10, 4037-4054. doi: 10.5194/bg-10-4037-2013

Lindstrom, E. J., Shcherbina, A. Y., Rainville, L., Farrar, J. T., Centurioni, L. R., Dong, S., et al. (2017). Autonomous multi-platform observations during the salinity processes in the upper-ocean regional study. Oceanography 30, 38-48. doi: 10.5670/oceanog.2017.218

Marrec, P., Gregori, G., Doglioli, A. M., Dugenne, M., Della Penna, A., Bhairy, N., et al. (2018). Coupling physics and biogeochemistry thanks to high-resolution observations of the phytoplankton community structure in the northwestern Mediterranean Sea. Biogeosciences 15, 1579-1606. doi: 10.5194/bg-15-15792018

McKinley, G. A., Fay, A. R., Lovenduski, N. S., and Pilcher, D. J. (2017). Natural variability and anthropogenic trends in the ocean carbon sink. Ann. Rev. Mar. Sci. 9, 125-150. doi: 10.1146/annurev-marine-010816060529

McLaughlin, K., Dickson, A., Weisberg, S. B., Coale, K., Elrod, V., Hunter, C., et al. (2017). An evaluation of ISFET sensors for coastal pH monitoring applications. Reg. Stud. Mar. Sci. 12, 11-18. doi: 10.1016/j.rsma.2017.02.008
McQuillan, J. S., and Robidart, J. C. (2017). Molecular-biological sensing in aquatic environments: recent developments and emerging capabilities. Curr. Opin. Biotechnol. 45, 43-50. doi: 10.1016/j.copbio.2016.11.022

Mignot, A., Ferrari, R., and Claustre, H. (2018). Floats with bio-optical sensors reveal what processes trigger the North Atlantic bloom. Nat. Commun. 9, 190-199. doi: 10.1038/s41467-017-02143-6

Miloslavich, P., Bax, N., Simmons, S., Klein, E., Appeltans, W., Aburto-Oropeza, O., et al. (2018). Essential ocean variables for sustained observations of marine biodiversity and ecosystems. Global Change Biol. 24, 2416-2433. doi: 10.1111/ gcb. 14108

Mongin, M., Baird, M. E., Tilbrook, B., Matear, R. J., Lenton, A., Herzfeld, M., et al. (2016). The exposure of the great barrier reef to ocean acidification. Nat. Commun. 7:10732. doi: 10.1038/ncomms10732

Muller-Karger, F. E., Miloslavich, P., Bax, N., Simmons, S., Costello, M. J., Pinto, I. S., et al. (2018). Advancing marine biological observations and data requirements of the complementary essential ocean variables (eovs) and essential biodiversity variables (ebvs) frameworks. Front. Mar. Sci. 5:211. doi: 10.3389/fmars.2018.00211

Newton, J. A., Feely, R. A., Jewett, E. B., Willamson, P., and Mathis, J. (2013). Global Ocean Acidification Observing Network: Requirements and Governance Plan, First Edition. Available at: https://www.pmel.noaa.gov/co2/GOA-ON/ GOA-ON_Plan_v1.0_April2014.doc (accessed October 2015).

Newton, J. A., Feely, R. A., Jewett, E. B., Willamson, P., and Mathis, J. (2015). Global Ocean Acidification Observing Network: Requirements and Governance Plan, Second Edition. Available at: http://www.goa-on.org/documents/general/ GOA-ON_2nd_edition_final.pdf (accessed May, 2019).

Orr, J. C., Fabry, V. J., Aumont, O., Bopp, L., Doney, S. C., Feely, R. A., et al. (2005). Anthropogenic ocean acidification over the twenty-first century and its impact on calcifying organisms. Nature 437, 681-686. doi: 10.1038/nature 04095

Palevsky, H. I., and Nicholson, D. P. (2018). The north atlantic biological pump: insights from the ocean observatories initiative irminger sea array. Oceanography 31, 42-49. doi: 10.5670/oceanog.2018.108

Rastrick, S. S. P., Graham, H., Azetsu-Scott, K., Calosi, P., Chierici, M., Fransson, A., et al. (2018). Using natural analogues to investigate the effects of climate change and ocean acidification on northern ecosystems. ICES J. Mar. Sci. 75, 2299-2311. doi: 10.1093/icesjms/fsy128

Riser, S. C., Swift, D., and Drucker, R. (2018). Profiling floats in SOCCOM: technical capabilities for studying the southern ocean. J. Geophys. Res. Oceans 123, 4055-4073. doi: 10.1002/2017JC013419

Sabine, C. L., Feely, R. A., Gruber, N., Key, R. M., Lee, K., Bullister, J. L., et al. (2004). The oceanic sink for anthropogenic CO2. Science 305, 367-371. doi: 10.1126/science. 1097403

Siedlecki, S. A., Kaplan, I. C., Hermann, A. J., Nguyen, T. T., Bond, N. A., Newton, J. A., et al. (2016). Experiments with seasonal forecasts of ocean conditions for the northern region of the california current upwelling system. Sci. Rep. 6:27203. doi: $10.1038 /$ srep 27203

Spaulding, R. S., DeGrandpre, M. D., Beck, J. C., Hart, R. D., Peterson, B., De Carlo, E. H., et al. (2014). Autonomous in situ measurements of seawater alkalinity. Environ. Sci. Technol. 48, 9573-9581. doi: 10.1021/es501615x

Sunday, J. M., Fabricius, K. E., Kroeker, K. J., Anderson, K. M., Brown, N. E., Barry, J. P., et al. (2016). Ocean acidification can mediate biodiversity shifts by changing biogenic habitat. Nat. Clim. Change 7, 81-85. doi: 10.1038/ nclimate3161

Sutton, A. J., Feely, R. A., Maenner-Jones, S., Musielewicz, S., Osborne, J., Dietrich, C., et al. (2018). Autonomous seawater pCO2 and pH time series from 40 surface buoys and the emergence of anthropogenic trends. Earth Syst. Sci. Data 11, 421-439. doi: 10.5194/essd-11-421-2019

Toole, J. M., Krishfield, R. A., Timmermans, M.-L., and Proshutinsky, A. (2011). The Ice-Tethered profiler: argo of the arctic. Oceanography 24, 126-135. doi: 10.5670/oceanog.2011.64

Turi, G., Lachkar, Z., Gruber, N., and Munnich, M. (2016). Climatic modulation of recent trends in ocean acidification in the California current system. Environ. Res. Lett. 11:014007. doi: 10.1088/1748-9326/11/1/01 4007

Vargas, C. A., Lagos, N. A., Lardies, M. A., Duarte, C., Manriquez, P. H., Aguilera, V. M., et al. (2017). Species-specific responses to ocean acidification should 
account for local adaptation and adaptive plasticity. Nat. Ecol. Evol. 1:0084. doi: 10.1038/s41559-017-0084

Wang, Z. A., Sonnichsen, F. N., Bradley, A. M., Hoering, H. A., Lanagan, T. M., Chu, S. N., et al. (2015). An in-situ sensor technology for simultaneous spectrophotometric measurements of seawater total dissolved inorganic carbon and pH. Environ. Sci. Technol. 49, 4441-4444. doi: 10.1021/es504 $893 n$

Williams, N. L., Juranek, L. W., Feely, R. A., Johnson, K. S., Sarmiento, J. L., Talley, L. D., et al. (2017). Calculating surface ocean $p \mathrm{CO} 2$ from biogeochemical argo floats equipped with pH: an uncertainty analysis. Global Biogeochem. Cycles 31, 591-604. doi: 10.1002/2016GB005541

Williams, N. L., Juranek, L. W., Feely, R. A., Russell, J. L., Johnson, K. S., and Hales, B. (2018). Assessment of the carbonate chemistry seasonal cycles in the southern ocean from persistent observational platforms. J. Geophys. Res. 123, 4833-4852. doi: 10.1029/2017JC012917
Conflict of Interest Statement: The authors declare that the research was conducted in the absence of any commercial or financial relationships that could be construed as a potential conflict of interest.

The reviewer PB declared a past co-authorship with one of the authors LK to the handling Editor.

Copyright (๑ 2019 Tilbrook, Jewett, DeGrandpre, Hernandez-Ayon, Feely, Gledhill, Hansson, Isensee, Kurz, Newton, Siedlecki, Chai, Dupont, Graco, Calvo, Greeley, Kapsenberg, Lebrec, Pelejero, Schoo and Telszewski. This is an open-access article distributed under the terms of the Creative Commons Attribution License (CC BY).

The use, distribution or reproduction in other forums is permitted, provided the original author(s) and the copyright owner(s) are credited and that the original publication in this journal is cited, in accordance with accepted academic practice. No use, distribution or reproduction is permitted which does not comply with these terms. 